\title{
Algoritmo de determinação do coeficiente de amortecimento em materiais refratários de alta alumina
}

\author{
Bruno de Castro Musolino
}

Dissertação apresentada à Escola de Engenharia de São Carlos da Universidade de São Paulo, como parte dos requisitos para obtenção do título de Mestre em Ciências, Programa de Engenharia Elétrica

ORIENTADOR: Prof. Dr. Carlos Dias Maciel ÁREA DE CONCENTRAÇÃO: Processamento Digital de Sinais 
AUTORIZO A REPRODUÇÃO E DIVULGAÇÃO TOTAL OU PARCIAL DESTE TRABALHO, POR QUALQUER MEIO CONVENCIONAL OU ELETRÔNICO, PARA FINS DE ESTUDO E PESQUISA, DESDE QUE CITADA A FONTE.

Ficha catalográfica preparada pela Seção de Tratamento da Informação do Serviço de Biblioteca - EESC/USP

Musolino, Bruno de Castro.

Algoritmo de determinação do coeficiente de amortecimento em materiais refratários de alta alumina / Bruno de Castro Musolino; orientador Carlos Dias Maciel. São Carlos, 2011.

Dissertação (Mestrado - Programa de Pós-Graduação em Engenharia Elétrica e Área de Concentração em

Processamento Digital de Sinais) -- Escola de Engenharia de São Carlos da Universidade de São Paulo, 2011.

1. Concreto refratário. 2. Amortecimento. 3. Choque térmico. 4. Análise de tempo-frequência. 5.

Viscoelasticidade. I. Título. 
FOLHA DE JULGAMENTO

Candidato: Engenheiro BRUNO DE CASTRO MUSOLINO

Título da tese: Algoritmo de determinação do coeficiente de amortecimento em materiais refratários de alta alumina.

Data da defesa: 18/07/2011:

\section{Comissão Julgadora:}

Prof. Titular José Carlos Pereira (Orientador Substituto)

(Escola de Engenharia de São Carlos/EESC)

Prof. Dr. Ailton Akira Shinoda

(Universidade Estadual Paulista "Julio de Mesquita Filho"/UNESP/campus de Ilha Solteira)

Prof. Associado José de Anchieta Rodrigues

(Universidade Federal de São Carlos/UFSCar)
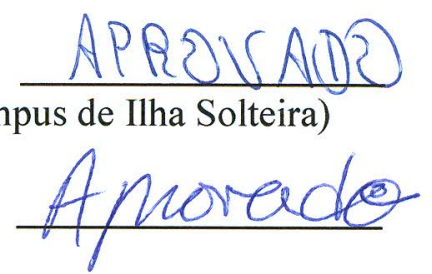

Resultado:

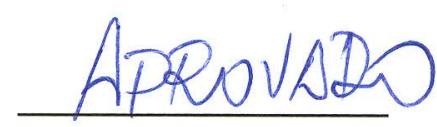

Coordenador do Programa de Pós-Graduação em Engenharia Elétrica:

Prof. Titular Denis Vinicius Coury

Presidente da Comissão de Pós-Graduação:

Prof. Associado Paulo Cesar Lima Segantine 
Dedicatória

Dedico este trabalho aos meus pais pela paciência, compreensão e toda dedicação para que eu chegasse a este momento. 
Eu gostaria primeiramente de agradecer ao Prof. Dr. Carlos Maciel, pela excelente orientação e todo conhecimento passado à mim. Agradeço também ao Henrique Alves, proprietário da ATCP e toda sua equipe, pelas oportunidades que me foram abertas, conhecimentos compartilhados, equipamentos cedidos, críticas e todo apoio concedido.

Agradeço também aos colegas de laboratório que me prestaram ajuda nos momentos que necessitei, em especial ao Jen John Lee, companheiro de experimentos e mais experimentos. Agradeço a todos os docentes das disciplinas que cursei e também aos que estavam sempre disponíveis para uma conversa quando essa se fazia necessária.

Agradeço aos funcionários da EESC, secretários, funcionários de limpeza, técnicos de laboratório e de informática e técnicos da manutenção, em especial à Jussara, ao Odair e ao Rui que sempre foram imensamente prestativos, pró-ativos e disponíveis.

Por fim, agradeço a Deus, toda minha família, namorada e amigos que sem dúvida contribuíram (e muito!) direta ou indiretamente durante todo este trabalho. 
"Eu quase que nada não sei. Mas desconfio de muita coisa." João Guimarães Rosa 


\section{Sumário}

Lista de Figuras

$\begin{array}{lll}\text { Lista de Tabelas } & \text { xv }\end{array}$

$\begin{array}{ll}\text { Resumo } & \text { xvii }\end{array}$

$\begin{array}{lcl}\text { Abstract } & \text { xix }\end{array}$

1 Introdução 1

2 Teoria 5

2.1 Amortecimento . . . . . . . . . . . . . . . . . . 5 5

2.1.1 Método do Decremento Logarítmico . . . . . . . . . . . . . 8

2.2 A Transformada Discreta de Fourier e a FFT . . . . . . . . . . . . . . . . . 9

$2.2 .1 \quad$ A FFT . . . . . . . . . . . . . . . . . . 10

2.3 Janelamento e Vazamento Spectral . . . . . . . . . . . . . . . . . . . 12

2.4 O Periodograma de Welch . . . . . . . . . . . . . . . . . . . 15

2.5 Short-Time Fourier Transform (Espectrograma) . . . . . . . . . . . . . . 17

2.6 O Algoritmo de Levenberg-Marquardt para Ajuste Não-Linear . . . . . . . . . 18

3 Materiais e Métodos

3.1 Matlab . . . . . . . . . . . . . . . . . . . 21

3.2 Aquisição do Sinal . . . . . . . . . . . . . . . . . . 22

3.3 Materiais para Análise . . . . . . . . . . . . . . . . . . . . 24

3.4 Suporte e Excitação do Material em Análise . . . . . . . . . . . . . . . . . . . 26

3.5 Método de Cálculo do Amortecimento . . . . . . . . . . . . . . . . . . . . . 27

4 Resultados $\quad 31$

4.1 Validação do Método de Cálculo . . . . . . . . . . . . . . . . . 31

4.2 Aplicação para a Barra de Alumina . . . . . . . . . . . . . . . . . . 33 
4.3 Aplicação para os Concretos Refratários . . . . . . . . . . . . . . . . 35

4.3.1 Refratário de Alta Alumina com Baixo Teor de Agregados . . . . . . . 36

4.3.2 Refratário de Alta Alumina com Alto Teor de Agregados . . . . . . . 39

4.3.3 Refratário de Silico-Aluminoso Impregnado com Coque . . . . . . . . 43

5 Discussão e Conclusão

5.1 Próximos Passos . . . . . . . . . . . . . . . . . . . . . 50

Referências Bibliográficas 


\section{Lista de Figuras}

FIGURA 2.1 Função senoidal aplicada a uma função em decaimento logarítmico. As flechas denotam pontos distantes de 1 período que poderiam ser utilizados para o cálculo do decremento logarítmico. Essa informação pode ser posteriormente utilizada para o cálculo do amortecimento do sistema. . . . . . . . . . 9

FIGURA 2.2 Estrutura do Algoritmo de Decimação no tempo Radix-2: Esquemático de cálculo da DFT de uma sequêcia de 8 pontos através de subsequências menores. . . . . . . . . . . . . . . . . . . . . . . . 1

FIGURA 2.3 Resposta em frequência de uma janela retangular com as principais características ressaltadas pelas flechas. A flecha superior denota a largura do lóbulo principal como sendo o ponto onde a amplitude da resposta em frequência cai a -3dB. A flecha intermediária aponta o nível máximo dos lóbulos laterais como sendo o ponto de máximo atingido pelo lóbulo adjacente ao pricipal e a flecha inferior ressalta a taxa de decaimento dos lóbulos laterais. . . . . . . 14

FIGURA 2.4 Comparação entre diversos tipos de janelas. (a) Janelas representadas no domínio do tempo (neste caso com 256 pontos). (b) Resposta em frequência das janelas representadas na figura $($ a $) \ldots \ldots \ldots$

FIGURA 2.5 (a) Chirp representando um sinal gerado por uma função senoidal variando de $0 \mathrm{~Hz}$ a $150 \mathrm{~Hz}$ em 2 segundos multiplicada por uma função exponencial com expoente negativo. (b) STFT resultante da análise do sinal da figura (a), a intensidade é representada pela temperatura da cor. . . . . . . . . 18

FIGURA 3.1 Microfone Behringer B-5 com condensador capacitivo e cápsula cardióide usado para aferir o sinal de ressonância. 
FIGURA 3.2 M-audio Fast Track Ultra utilizado para a aquisição de sinal via USB. Imagem retirada de http://www.assessoriatecnica.com.br. . . . . . . . . . . . 23

FIGURA 3.3 Amostras testadas para determinação do amortecimento. (A) Amostra de alumina densa, (B) amostra de concreto refratário comercial de alta alumina com danos por choque térmico e $(\mathrm{C})$ amostra de concreto refratário comercial de alta alumina sem danos por choque térmico. . . . . . . . . . . . . . 25

FIGURA 3.4 Formato padrão das amostras ensaiadas. . . . . . . . . . . . . . . . . 25

FIGURA 3.5 (a) Suporte de precisão com ajuste automático para corpos de prova. Permite testes com condições de contorno para o modo flexural e longitudinal ou para o modo torcional. (b) Sonelastic IED (esquerda) e atuador mecânico (direita) . . . . . . . . . . . . . . . . . . . . 26

FIGURA 3.6 Fluxograma da aquisição de sinal como o algoritmo implementado no MATLAB. . . . . . . . . . . . . . . . . . . . . . . . . 27

FIGURA 3.7 Fluxograma do pré-processamento em uma sequência estruturada. . . 28

FIGURA 3.8 Fluxograma da versão estruturada do algoritmo para determinação do amortecimento. . . . . . . . . . . . . . . . . . . . 30

FIGURA 4.1 Variação de amplitude com o tempo do sinal simulado gerado a partir do modelo viscoelástico de ressonância somado a um ruído branco gaussiano com relação sinal-ruído média de 30dB. . . . . . . . . . . . . . . . . . . . 32

FIGURA 4.2 Espectro de magnitude dos primeiros 1024 pontos do sinal simulado representado na Figura $4.1 \ldots \ldots$. . . . . . . . . . . . . . . . . 33

FIGURA 4.3 Variação de potência da frequência em função do tempo amostrado calculada como sendo a ressonância contida no sinal. A frequência encontrada é de $4 \mathrm{kHz}$ e o amortecimento calculado através do método é de $2.001 \cdot 10^{-4}$. . 33

FIGURA 4.4 Short-Time Fourier Transform do sinal gerado pela simulação do modelo viscoelástico de ressonância. As cores representando a amplitude do sinal conforme exibido na caixa ao lado do gráfico. . . . . . . . . . . . . . . . 34

FIGURA 4.5 Sinal originário do impacto gerado pelo Sonelastic IED na barra de alumina e adquirido através da placa do microfone Behringer B-5 e da placa de aquisição M-Audio Fast Track Ultra. . . . . . . . . . . . . . . . . . . . . . 3 
FIGURA 4.6 Espectro de magnitudes calculado para os primeiros 1024 pontos do sinal de ressonância da barra de alumina. . . . . . . . . . . . . . . . . . 35

FIGURA 4.7 Evolução da potência com o tempo amostrado da frequência 9875,3 Hz e o amortecimento calculado através do ajuste do modelo (curva em vermelho) . . . . . . . . . . . . . . . . . . . . 35

FIGURA 4.8 Sinais amostrados da amplitude de vibração pelo tempo de amostragem. (a) Sinal da amostra de concreto refratário com baixo teor de agregados (amostra 2) sem dano. (b) Sinal da amostra de concreto refratário com baixo teor de agregados (amostra 3 ) com dano por choque térmico. . . . . . . . . . 36

FIGURA 4.9 Espectros de magnitude dos primeiros 1024 pontos dos sinais representados na Figura 4.8. (a) Espectro de magnitude da amostra de concreto refratário com baixo teor de agregados (amostra 2) sem dano. (b) Espectro de magnitude da amostra de concreto refratário com baixo teor de agregados (amostra 3) com dano por choque térmico. . . . . . . . . . . . . 37

FIGURA 4.10 Variação da potência para a principal ressonância de cada amostra, modelos ajustados sobre a curva, valor das frequências de ressonância e valor do amortecimento calculado. (a) Concreto refratário com baixo teor de agregados (amostra 2) sem dano. (b) Concreto refratário com baixo teor de agregados (amostra 3) com dano por choque térmico. . . . . . . . . . . . . . . 38

FIGURA 4.11 Sinais amostrados da amplitude de vibração pelo tempo de amostragem. (a) Sinal da amostra de concreto refratário com alto teor de agregados (amostra 4) sem dano. (b) Sinal da amostra de concreto refratário com alto teor de agregados (amostra 5) com dano por choque térmico.

FIGURA 4.12 Espectros de magnitude dos primeiros 1024 pontos dos sinais representados na Figura 4.11. (a) Espectro de magnitude da amostra de concreto refratário com alto teor de agregados (amostra 4) sem dano. (b) Espectro de magnitude da amostra de concreto refratário com alto teor de agregados (amostra 5) com dano por choque térmico. . . . . . . . . . . . . . . 41 
FIGURA 4.13 Variação da potência para a principal ressonância de cada amostra, modelos ajustados sobre a curva, valor das frequências de ressonância e valor do amortecimento calculado. (a) Concreto refratário com alto teor de agregados (amostra 4) sem dano. (b) Concreto refratário com alto teor de agregados (amostra 5) com dano por choque térmico. . . . . . . . . . . . . .

FIGURA 4.14 Sinais amostrados da amplitude de vibração pelo tempo de amostragem. (a) Sinal da amostra de concreto refratário impregnado com coque (amostra 6) sem dano. (b) Sinal da amostra de concreto refratário impregnado com coque (amostra 7) com dano por choque térmico. . . . . . . . . . . . . . 44

FIGURA 4.15 Espectros de magnitude dos primeiros 1024 pontos dos sinais representados na Figura 4.14. (a) Espectro de magnitude da amostra de concreto refratário impregnado com coque (amostra 6) sem dano. (b) Espectro de magnitude da amostra de concreto refratário impregnado com coque (amostra 7) com dano por choque térmico. . . . . . . . . . . . . . . . . . . . 45

FIGURA 4.16 Variação da potência para a principal ressonância de cada amostra, modelos ajustados sobre a curva, valor das frequências de ressonância e valor do amortecimento calculado. (a) Concreto refratário impregnado com coque (amostra 6) sem dano. (b) Concreto refratário impregnado com coque (amostra 7) com dano por choque térmico. . . . . . . . . . . . . . . . . . . . 46 


\section{Lista de Tabelas}

TABELA 2.1 Comparação das Principais Característica de Diversas Funções de Janelamento . . . . . . . . . . . . . . . . . . . 15

TABELA 3.1 Resumo das amostras utilizadas no ensaios de amortecimento . . . . 24

TABELA 4.1 Parâmetros utilizados para a simulação de um sinal de ressonância através do uso de um modelo viscoelástico . . . . . . . . . . . . . . . . . 32

TABELA 4.2 Resumo dos resultados encontrados para as amostras de concreto refratário de alta alumina com baixo teor de agregados . . . . . . . . . . . 39

TABELA 4.3 Resumo dos resultados encontrados para as amostras de concreto refratário com alto teor de agregados . . . . . . . . . . . . . . . . 43

TABELA 4.4 Resumo dos resultados encontrados para as amostras de concreto refratário impregnado com coque . . . . . . . . . . . . . . . . . 47 


\section{Resumo}

Musolino, Bruno. Algoritmo de determinação do coeficiente de amortecimento em materiais refratários de alta alumina. 2011. 55 f. Dissertação. Escola de Engenharia de São Carlos, Universidade de São Paulo, São Carlos, 2011.

O amortecimento, fenômeno pelo qual energia mecânica em um sistema dinâmico é dissipada, é uma das propriedades mais sensíveis dos materiais quanto a presença de trincas e microtrincas.

O estudo do amortecimento já é bem estabelecido em áreas como engenharia civil, em que é de importância na resistência mecânica de um sistema sujeito a abalos sísmicos e vibrações, porém vem sendo cada vez mais estudado na indústria de materiais para analisar e quantificar o dano em concretos refratários que sofrem ciclos de choque térmico.

Este trabalho apresenta uma metodologia e algoritmo para a determinação do amortecimento das ressonâncias de um material, para avaliação de danos em concretos refratários, através da análise espectral de tempo-frequência. São também apresentados os resultados obtidos para um sinal simulado, uma barra de alumina densa, um par de barras de concreto refratário comercial de alta alumina com baixo teor de agregados, um par de barras de concreto refratário comercial de alta alumina com alto teor de agregados e um par de barras de concreto refratário silico-aluminoso impregnado com coque, sendo para os pares uma amostra com e outra sem dano por choque-térmico.

Com o uso do método foi possível recuperar o valor do amortecimento e a frequência usada para gerar o sinal simulado. O resultado apresentado para a alumina é compatível com o valor encontrado em literatura e, com o resultado obtido para os concretos refratários, foi possível mostrar o potencial de aplicação do método para caracterização de dano, sendo significativa a diferença do amortecimento do concreto com dano para o concreto sem dano. 
Palavras-chaves: Amortecimento, concreto refratário, choque-térmico, análise de tempofrequência, viscoelasticidade. 


\section{Abstract}

Musolino, Bruno. Algorithm for damping factor calculus in high alumina castables. 2011. 55 p. Dissertation. Escola de Engenharia de São Carlos, Universidade de São Paulo, São Carlos, 2011.

Damping, phenomenon by which mechanical energy is reduced in dynamic systems, is one of the most sensible properties of materials in relation to the presence of cracks and micro-cracks.

The study of the damping is well stablished in areas such as civil engineering, where it has fundamental importance in the mechanical resistance of a system exposed to seismic waves or vibration, although it is beginning to be used more often in the material industry to analyze and quantify the damage in castables that suffered thermal-shock cycles.

This work presents a methodology and an algorithm to determine the resonance's damping factors of a material, to evaluate the damage caused by thermal shock in castables, through the use of time-frequency spectral analysis. Results are presented for a simulated signal, an alumina beam, a pair of commercial high alumina with low-aggregate content castable, a pair of high alumina with high-aggregate content castable and a pair of silico-aluminous castable impregnated with coke. Each pair contains one sample with damage through thermal-shock cycle(s) and the other without.

By using this method it was possible to retrieve the damping value and frequency used to generate the simulated signal. The result for the alumina beam was in accordance to the literature values and, with the results achieved for the castables, it was possible to expose the potential application of the method to characterize damage: there were a considerable difference between the damping value of the castables with and without damages. 
Keywords: Damping, castables, thermal-shock, time-frequency analysis, viscoelasticity. 


\section{Capítulo 1}

\section{Introdução}

O amortecimento ou atrito interno é uma das propriedades mais sensíveis de materiais e estruturas, tanto em escala macro quanto microscópica (Lazan, 1968), sendo particularmente sensível à presença de trincas e micro-trincas (Dieterle e Bachmann, 1981).

Além da aplicação clássica no estudo de metais e da aplicação na área de engenharia civil (devido à importância do amortecimento para a integridade de estruturas no caso de abalos sísmicos) a caracterização do amortecimento também vem sendo empregada no estudo de concretos refratários para a avaliação do dano por choque térmico (Coppola e Bradt, 1973; Tonnesen e Telle, 2007).

A tensão mecânica induzida pelo gradiente de temperatura do choque térmico provoca a nucleação e propagação de micro-trincas e trincas que degradam as propriedades mecânicas do material determinando, em grande parte, a sua vida útil (Hasselman, 1969; Kingery, 1955). A nucleação e evolução destas micro-trincas e trincas podem ser monitoradas com a caracterização do amortecimento (Coppola e Bradt, 1973; Chowdhury, 1999; Tonnesen e Telle, 2007). A caracterização do amortecimento também é empregada para a verificação da qualidade e resistência de soldas e juntas, análise de dano de maquinaria industrial e motores e ajuste de salas acústicas (De Silva, 2007).

O amortecimento é o fenômeno pelo qual a energia mecânica de um sistema dinâmico é dissipada (De Silva, 2007), principalmente pela conversão em calor por forças dissipativas. $\mathrm{O}$ amortecimento de um sistema ou material pode ser classificado de três formas principais: interno, estrutural e fluídico. O interno está associado aos defeitos na microestrutura, granularidade e impurezas do material e a efeitos termoelásticos causados por gradientes locais de 
temperatura. Já o estrutural está associado a perdas de energia por atrito em juntas, parafusos e articulações semirrígidas. Por último, o fluídico ocorre por resistência ao arraste em meio fluídico, por exemplo a conversão de energia cinética de um pêndulo em energia térmica para o ar. Neste trabalho o interesse é pela avaliação do amortecimento interno.

Existem diversos métodos para a determinação do amortecimento interno, sendo os mais utilizados os do decremento logarítmico e da largura de banda de meia potência. A escolha do método depende principalmente da faixa do amortecimento e da frequência de vibração (De Silva, 2007). O método do decremento logarítmico consiste em calcular o amortecimento a partir da atenuação da resposta acústica do material ou estrutura após uma excitação por impulso. O método da largura de banda de meia potência consiste em, através da análise em frequência do sinal oriundo da vibração, calcular o amortecimento a partir da relação entre a largura de banda e a frequência central de uma ressonância. Ambos os métodos consideram um modelo para os cálculos, normalmente o modelo de amortecimento viscoelástico.

Este trabalho foi motivado pela necessidade de refinar a técnica de excitação por impulso para a caracterização dos módulos elásticos dinâmicos (ASTM, 1995) e pelo desejo de incorporar nesta técnica a caracterização simultânea do amortecimento utilizando o método do decremento logarítmico.

A técnica de excitação por impulso consiste essencialmente em excitar, através de um impacto mecânico, o modo de ressonância flexural, torcional ou longitudinal fundamental de uma amostra em formato de barra de secção retangular, e calcular os módulos elásticos dinâmicos a partir das frequências encontradas, dimensões e massa da amostra (Pickett, 1945).

A excitação de um determinado modo em particular é realizada impondo-se as condições de contorno mecânicas e de excitação adequadas. Contudo, dificilmente se consegue excitar um único modo de vibração. Em função desta dificuldade, a aplicação do método do decremento logarítmico no domínio do tempo possui um componente adicional de incerteza ao levar em consideração a resposta de modos de vibração menos favorecidos pelas condições de contorno. Os modos indesejados também aumentam a incerteza dos módulos elásticos quando o cálculo da frequiência realizado pelo sistema de medição é feito através do período do sinal captado, como acontece em métodos baseados em zero-crossing (Lemmens, 1990).

O objetivo deste trabalho é desenvolver um algoritmo que resolva bem os problemas descritos com uma análise de tempo-frequência, através do qual o decremento logarítmico é obtido a partir da atenuação exclusiva da frequência correspondente ao modo de vibração favorecido 
pelas condições de contorno, garantindo, assim, a discriminação da frequência analisada, eliminando a influência de outros modos de vibração e minimizando a deterioração causada por ruído.

Estes benefícios são particularmente bem vindos no caso de materiais que sofreram alto dano microestrutural, por exemplo no caso de concretos refratários submetidos a choques térmicos e de concretos estruturais submetidos a cargas elevadas, em que o dano eleva o amortecimento de forma expressiva, degrada a razão sinal/ruído do sinal e gera modos de vibração espúrios.

Neste trabalho será tratada a metodologia e algoritmo para a determinação do amortecimento através do sinal de ressonância gerado pelo do impacto de um aparato mecânico no corpo do material ensaiado. A seção Teoria (Capítulo 2) apresenta os conceitos básicos e as principais equações que descrevem o problema. Na seção Materiais e Métodos (Capítulo 3) são apresentados os corpos de prova, rotina de ensaio, software e equipamentos utilizados além do algoritmo de cálculo. Na seção Resultados (Capítulo 4) são exibidos resultados da análise de um sinal simulado, as características determinadas para os corpos de prova e um resultado da aplicação em refratários. Por fim, a seção Discussão e Conclusão (Capítulo 5) apresenta as conclusões deste trabalho. 


\section{Capítulo 2}

\section{Teoria}

Neste capítulo descrevem-se os conceitos e métodos fundamentais para o entendimento dos algoritmos do capítulo seguinte.

\subsection{Amortecimento}

Em sistemas dinâmicos, amortecimento é o fenômeno pelo qual energia mecânica é dissipada (De Silva, 2007). O seu conhecimento é importante para a utilização, análise e teste de um sistema. Conhecer como uma estrutura dissipa energia mecânica permite impor restrições sobre a excitação dinâmica que o sistema pode suportar.

De acordo com De Silva (2007), o estudo da perda de energia mecânica de um sistema é focado, principalmente, em três mecanismos primários de amortecimento: amortecimento interno (em materiais), amortecimento estrutural (em juntas e interfaces) e amortecimento fluídico (pela interação entre estrutura e um fluido).

Amortecimento estrutural é causado pela movimentação relativa entre diferentes componentes de uma estrutura e o amortecimento fluídico é oriundo da força de arrasto gerada pela movimentação da superfície da estrutura em relação a um meio líquido ou gasoso envolvendo a estrutura.

Segundo Lazan (1968), o amortecimento é uma das propriedades mais sensíveis de materiais e estruturas, tanto em escala macro como microscópica, sendo particularmente sensível a trincas e micro-trincas (Dieterle e Bachmann, 1981). Este pode ser causado por uma combinação de diversos mecanismos físicos fundamentais como granularidade e impurezas, 
efeitos termoelásticos causados por gradientes locais de temperatura resultante de excitação não-uniforme, correntes de eddy em materiais ferromagnéticos (também chamada de correntes de Foucault), movimentos de cadeias em polímeros e etc. Diversos modelos foram considerados para representar a perda de energia em materiais, porém, nenhum é capaz de representar bem todos os mecanismos de amortecimento (De Silva, 2007).

Considera-se um sistema mecânico com $n$ graus de liberdade, seu movimento sendo descrito pelo vetor $x$ de $n$ diferentes coordenadas com $x_{i}$, representando o movimento independente de cada elemento inercial. Para pequenos deslocamentos, uma mola linear pode ser considerada (De Silva, 2007). A equação do movimento pode ser descrita na forma matricial por

$$
\mathbf{M} \ddot{x}+d+\mathbf{K} x=\mathbf{f}(\mathbf{t})
$$

em que $\mathbf{M}$ é a matriz da massa inercial, $\mathbf{K}$ é a matriz de constantes elásticas e $\mathbf{f}(\mathbf{t})$ é o vetor de funções de força atuando no sistema. No caso em que o sistema oscila livremente temse $f(t)=0$. O vetor de amortecimentos $d$ é geralmente uma função não-linear de $x$ e $\dot{x}$. Devido a alta complexidade dos modelos de amortecimento, geralmente é escolhido o modelo viscoelástico que permite uma análise matemática simplificada (De Silva, 2007). Este modelo considera que o amortecimento é diretamente proporcional a velocidade de deslocamento $\dot{x}$, que neste caso, considerando uma oscilação livre, a equação acima pode ser rescrita como

$$
\mathbf{M} \ddot{x}+\mathbf{C} \dot{x}+\mathbf{K} x=0 .
$$

Um sistema massa-mola-amortecedor com 1 grau de liberdade, oscilando livremente, tem seu movimento descrito pela equação

$$
m \ddot{x}+c \dot{x}+k x=0,
$$

na qual $m$ é a massa, $c$ é a constante de amortecimento e $k$ é a constante elástica da mola. Reescrevendo a relação acima, tem-se

$$
\ddot{x}+\frac{c}{m} \dot{x}+\frac{k}{m} x=0 .
$$


Definindo-se

$$
\omega_{n}=\sqrt{\frac{k}{m}}
$$

$\mathrm{e}$

$$
\zeta=\frac{c}{2 \sqrt{k m}},
$$

sendo $\omega_{n}$ a frequência de ressonância natural e $\zeta$ a taxa de amortecimento ou apenas amortecimento. Reescrevendo-se a equação (2.4) em função dos novos parâmetros tem-se

$$
\ddot{x}+2 \zeta \omega_{n} \dot{x}+\omega_{n}^{2} x=0
$$

(Thorby, 2008), e assumindo a solução

$$
x=e^{\gamma t}
$$

chega-se a $\gamma$ sendo descrito por

$$
\gamma=\omega_{n}\left(-\zeta \pm \sqrt{\zeta^{2}-1}\right)
$$

O comportamento do sistema descrito pela equação (2.4) depende da solução de $\gamma$ e as maiores diferenças aparecem quando $\zeta$ tem duas soluções reais $(\zeta>1)$, uma solução real $(\zeta=1)$ ou duas soluções complexas $(0 \leq \zeta<1)$ (Papoulis, 1984).

Os casos em que $\zeta=1$ e $\zeta>1$ são conhecidos como sistemas sobreamortecido e criticamente amortecido. Ambos os sistemas são não-oscilatórios e diferem apenas no tempo de estabilização (De Silva, 2007). Quando o amortecimento é crítico o sistema tem o menor tempo de estabilização possível e conforme o valor do amortecimento aumenta o sistema tende a uma estabilização mais lenta.

Quando $\gamma$ tem duas soluções complexas o sistema é oscilatório e é chamado de subamortecido. Este pode ser descrito genericamente por

$$
x(t)=A_{0} \cdot e^{-\zeta \omega_{n} t} \cdot \cos \left(\omega_{d} t+\phi\right)
$$

no qual $A_{0}$ é a amplitude inicial da oscilação, $\phi$ é uma variável aleatória uniformemente distribuída representando a fase inicial, $\omega_{n}$ é chamada de frequência natural de vibração e $\omega_{d}$ é a 
frequência amortecida de vibração, sendo descrita por (De Silva, 2007)

$$
\omega_{d}=\omega_{n} \sqrt{1-\zeta^{2}} .
$$

A partir da solução do sistema subamortecido, Equação 2.10, estatísticamente o valor RMS da envoltória do sinal medido, em que haja um ruído gaussiano aditivo de média nula com valor RMS $A_{n}$ e descorrelacionado com o sinal, pode ser dado por

$$
E[X(t)]=\sqrt{{\frac{A_{0}^{2}}{2}}^{2} e^{-2 \tau t}+A_{n}^{2}}
$$

em que $E[X(t)]$ é o valor esperado da variável aleatória $X$ naquele instante e $\tau$ é dado por

$$
\tau=\zeta \omega_{n}
$$

\subsubsection{Método do Decremento Logarítmico}

O decremento logarítmico consiste em comparar pontos distantes de $i$ períodos, em uma oscilação livre amortecida de um sistema com um grau de liberdade, a fim de encontrar a perda de amplitude por ciclo de oscilação.

Sendo o período de oscilação igual a

$$
T_{d}=\frac{2 \pi}{\omega_{d}},
$$

pode-se então determinar que

$$
\frac{x(t)}{x\left(t+i T_{d}\right)}=e^{\zeta \omega_{n} T_{d} i}
$$

A Figura 2.1 mostra um sistema SDOF (sistemas com um grau de liberdade, do inglês Single Degree of Freedom) em oscilação livre amortecida e denota os pontos distantes de um número inteiro de períodos a serem utilizados no cálculo do decremento logarítmico.

Substituindo $\omega_{n}$ e $T_{d}$ pelas equações (2.11) e (2.14) respectivamente, obtem-se o decremento logarítmico por período de oscilação, $\lambda$, como

$$
\lambda=\frac{1}{i} \ln \left(\frac{x(t)}{x\left(t+i T_{d}\right)}\right)=\frac{2 \pi \zeta}{\sqrt{1-\zeta^{2}}} .
$$




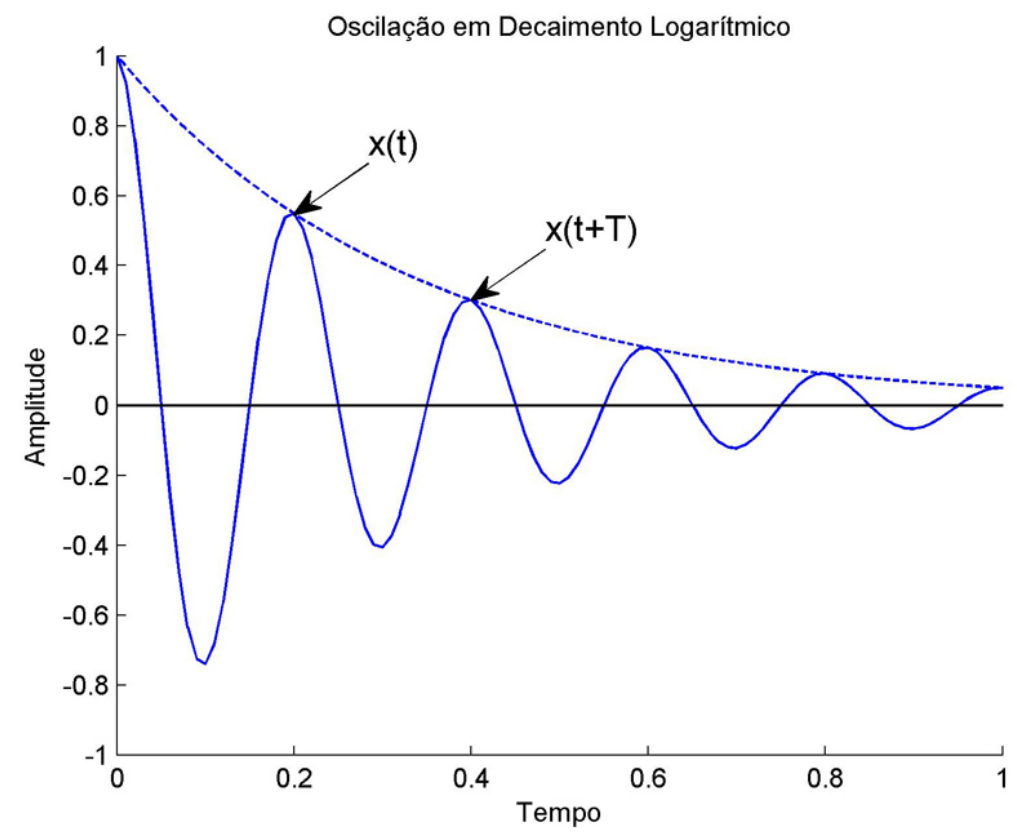

Figura 2.1: Função senoidal aplicada a uma função em decaimento logarítmico. As flechas denotam pontos distantes de 1 período que poderiam ser utilizados para o cálculo do decremento logarítmico. Essa informação pode ser posteriormente utilizada para o cálculo do amortecimento do sistema.

A partir da equação acima o amortecimento $\zeta$ é determinado através do decremento logarítmico $\lambda$ como descrito pela relação

$$
\zeta=\frac{\lambda}{\sqrt{4 \pi^{2}+\lambda^{2}}}
$$

\subsection{A Transformada Discreta de Fourier e a FFT}

A representação em frequência conforme utilizada neste trabalho é obtida através de um sinal amostrado e computado em um processador. Esta representação é dada pela transformada de Fourier $X\left(e^{j \omega}\right)$ de uma sequência $x[n]$, no entanto, $\omega$ é uma variável contínua e sendo assim não é conveniente para a computação (Proakis e Manolakis, 1996).

Para sequências de duração finita é possível desenvolver uma representação alternativa para a transformada de Fourier chamada Transformada Discreta de Fourier (DFT - Discrete Fourier Transform) (Oppenheim et al., 1989).

Ao usar-se a DFT em uma sequência $x[n]$ finita implica em assumir que essa sequência 
finita corresponda a um período de uma sequência infinita e periódica $x_{p}[n]$ (Proakis e Manolakis, 1996). Em casos nos quais a sequência não corresponde ao período de uma sequência periódica ocorre o fenômeno conhecido como leakage, ou vazamento espectral, este será discutido na seção 2.3 .

A Transformada Discreta de Fourier de uma sequência $x[n] \operatorname{com} N$ amostras é dada por

$$
X[k]=\sum_{n=0}^{N-1} x[n] e^{-\frac{j 2 \pi}{N} n k},
$$

em que $k$ é um índice inteiro de $N$ frequências igualmente espaçadas por $2 \pi / N$.

\subsubsection{A FFT}

FFT ou Fast Fourier Transform é o nome dado ao conjunto de algoritmos que realizam a computação da DFT de forma rápida e eficiente. Esse conjunto de algoritmos teve início com a publicação do artigo de Cooley e Tukey (1965), An algorithm for the machine calculation of complex Fourier series.

A equação da FFT é essencialmente igual a da DFT já definida anteriormente, seu cálculo compreende de

$$
X[k]=\sum_{n=0}^{N-1} x[n] W_{N}^{n k},
$$

em que $W_{N}^{k n}$ é conhecido como twiddle e é definido como

$$
W_{N}^{n k}=e^{-\frac{j 2 \pi}{N} n k} \text { para } n=0,1, \ldots, N-1
$$

O princípio fundamental dos algoritmos de FFT é a decomposição da computação da DFT de uma sequência de tamanho $N$ em sucessivas DFT de tamanhos menores (Oppenheim et al., 1989). O algoritmo descrito aqui é conhecido como decimação no tempo, este tem seu nome devido ao processo de calcular a DFT através da subdivisão da sequência $x[n]$, conhecida como sequência temporal, em sequências menores.

O twiddle é a origem das maiores otimizações possíveis ao algoritmo de cálculo da DFT. Através da exploração das suas propriedades de simetria e periodicidade, o algoritmo de decimação no tempo subdivide uma sequência de tamanho $\mathrm{N}$ em sequências menores, sucessivamente, até que o cálculo da DFT da sequência de $\mathrm{N}$ pontos possa ser efetuado através de 
diversas subsequências de 2 pontos. Esse algoritmo, devido a sequência básica ter apenas 2 pontos, é conhecido como Radix-2 DIT, do inglês, Decimation-In-Time.

Considerando o caso especial onde $N=2^{v}$, pode-se considerar calcular $X[k]$ separando $x[n]$ em duas DFTs de $(N / 2)$ pontos, uma com os $n$ pares e outra com os ímpares (Oppenheim et al., 1989).

$$
\begin{aligned}
X[k] & =\sum_{r=0}^{(N / 2)-1} x[2 r] W_{N}^{2 r k}+\sum_{r=0}^{(N / 2)-1} x[2 r+1] W_{N}^{(2 r+1) k} \\
& =\sum_{r=0}^{(N / 2)-1} x[2 r] W_{N / 2}^{r k}+W_{N}^{k} \sum_{r=0}^{(N / 2)-1} x[2 r+1] W_{N / 2}^{r k} .
\end{aligned}
$$

Este processo é então repetido para cada uma das subsequências até que todas as DFT sejam para subsequências de 2 pontos, levando a uma estrutura de cálculo como observada na Figura 2.2 no caso de uma sequência inicial de 8 pontos.

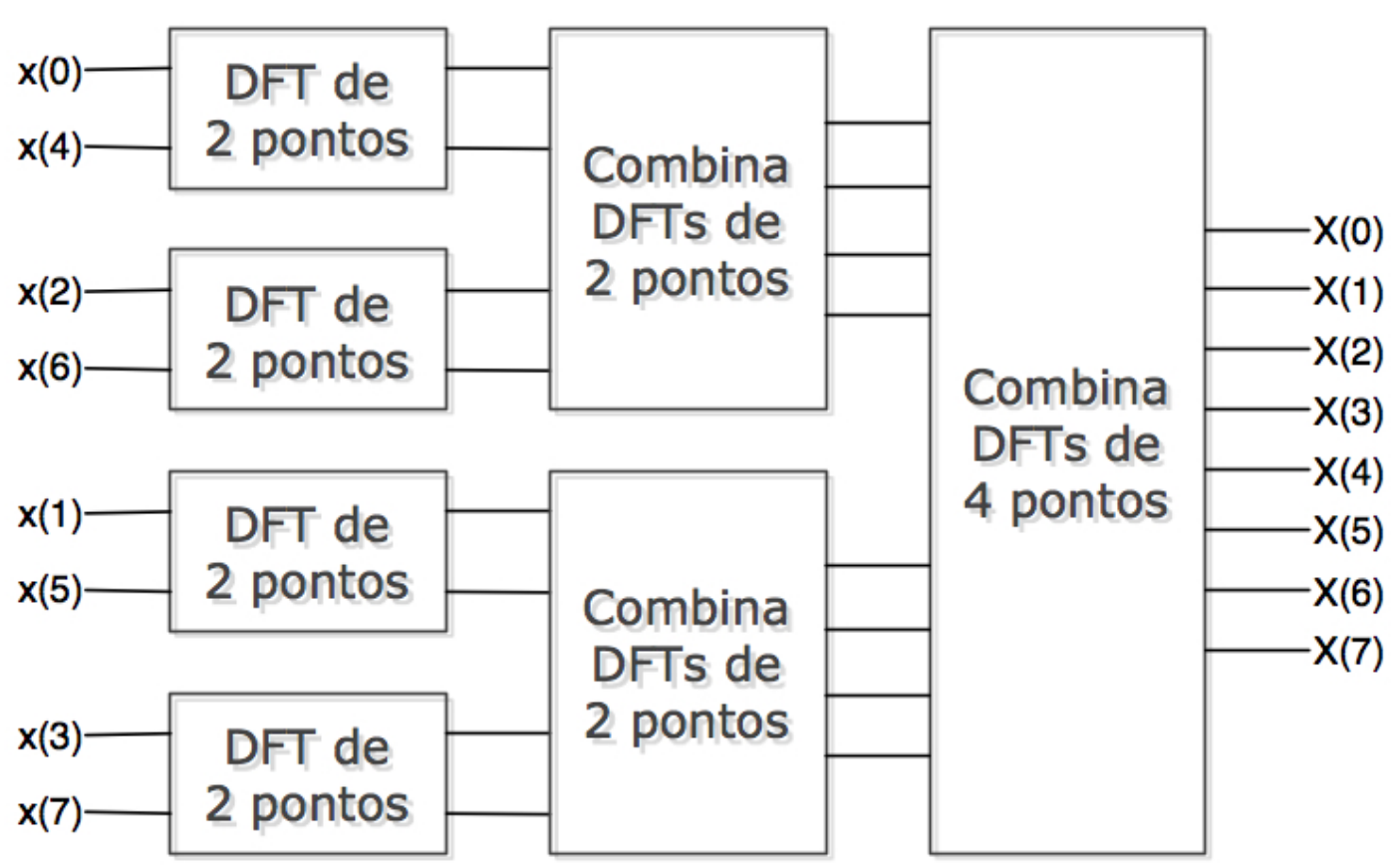

Figura 2.2: Estrutura do Algoritmo de Decimação no tempo Radix-2: Esquemático de cálculo da DFT de uma sequêcia de 8 pontos através de subsequências menores.

Conforme pode ser observado na equação (2.18) o cálculo da DFT com entrada complexa envolve $N^{2}$ multiplicações complexas ( $4 N^{2}$ multiplicações reais e $2 N^{2}$ somas reais) e $(N-1)^{2}$ somas complexas $\left(2(N-1)^{2}\right.$ somas reais). Computacionalmente falando, o algoritmo de cál- 
culo da DFT tem complexidade $O\left(N^{2}\right)$. O algoritmo Radix-2 por sua vez faz com que esse número de operações seja drasticamente reduzido, totalizando $(N / 2) \log _{2} N$ multiplicações complexas (2N $\log _{2} N$ multiplicações reais e $N \log _{2} N$ somas reais) e $N \log _{2} N$ somas complexas ( $2 N \log _{2} N$ somas reais), uma complexidade computacional de $O\left(N \log _{2} N\right)$. Para valores grandes de $\mathrm{N}$ essa redução é bastante significativa, para uma sequência com $N=1024$ pontos, o cálculo da DFT exige no total 4.194 .304 multiplicações contra 20.480 multiplicações do algoritmo de FFT.

É importante notar que o algoritmo Radix-2 tem como critério de entrada sequência apenas com total de pontos que sejam potência de 2 . Caso a sequência não possua o número de pontos necessário, o seu tamanho pode ser ajustado de duas maneiras: reduzindo o número de pontos para a potência de 2 consecutivamente inferior ou, pela utilização de zero-padding, aumentando o número de pontos da sequência para a potência de 2 imediatamente superior pela adição de zeros ao início ou final da sequência.

\subsection{Janelamento e Vazamento Spectral}

Dada a essência limitada em tamanho da função a ser avaliada através de uma DFT, dizse que esta é o resultado de um janelamento aplicado a uma sequência de tamanho maior ou mesmo infinito.

Janela é o nome dado a uma função matemática que possui valor nulo fora de um determinado intervalo. Por exemplo, uma função que possui valor constante dentro de um intervalo e zero fora deste é conhecida como janela retangular, sua função é, por exemplo,

$$
w r[n]= \begin{cases}1, & \text { se } 0 \leq n \leq N-1 \\ 0, & \text { c.c. }\end{cases}
$$

Uma função senoidal como $\cos \left(\omega_{0} t\right)$ tem transformada de Fourier igual a zero exceto em $\pm \omega_{0}$. O janelamento faz com que o valor da transformada de Fourier dessa função seja diferente de zero também nas frequências diferentes de $\pm \omega_{0}$.

Em sinais em que há mais de uma senóide, esse efeito pode causar interferência na capacidade de distinguir ambas frequências porque as frequências são muito próximas se comparadas à resolução espectral ou porque a diferença entre as amplitudes é muito grande. 
O vazamento espectral tem origem na propriedade da transformada de Fourier que determina que sinais multiplicados no tempo tem seus espectros de frequências convoluídos. Dado que a DFT de um sinal janelado é dada por

$$
X[k]=\sum_{n=0}^{N-1} w[n] s[n] e^{-\frac{j 2 \pi}{N} n k},
$$

em que $w[n]$ é a função de janelamento definida em $0 \leq n \leq N-1$ e $s[n]$ é a sequência que representa o sinal amostrado no tempo. O resultado da DFT pode ser rescrito em função dos resultados da DFT de $w[n]$ e de $x[n]$ como

$$
X[k]=W[k] * S[k] .
$$

A resposta em frequência de uma janela retangular, assim como os parâmetros de maior importância na seleção de uma janela para análise espectral, podem ser observados na Figura 2.3.

Dentre as propriedades da resposta em frequência de uma determinada janela, algumas são responsáveis pela escolha da janela ideal. As principais característica são: largura do lóbulo Principal, nível máximo dos lóbulos laterais e taxa de decaimento dos lóbulos laterais.

Dessas três propriedades, a largura do lóbulo principal e o nível máximo dos lóbulos laterais são os principais determinantes pela distinção de frequências muito próximas do sinal analisado e a taxa de decaimento dos lóbulos laterais é importante para a distinção de picos com diferença muito grande das amplitudes.

Apesar de qualquer função arbitrária poder ser utilizada como janela para um sinal, algumas possuem propriedades mais interessantes do que outras. Diversos artigos foram publicados com resultados de utilização de janelas. A janela retangular, por exemplo, apresenta uma boa resolução espectral devido à sua estreita largura do lóbulo principal, em contrapartida possui um máximo de lóbulo lateral de 13,3dB.

A Tabela 2.1 denota as principais características de diversas janelas usadas na literatura (Proakis e Manolakis, 1996; Oppenheim et al., 1989).

Associada à Tabela 2.1, a Figura 2.4 sintetiza as características temporais (a) e em frequência (b) de algumas janelas em uma imagem.

\footnotetext{
${ }^{1}$ Valores obtidos com o uso da ferramenta wvtool do MATLAB.
} 


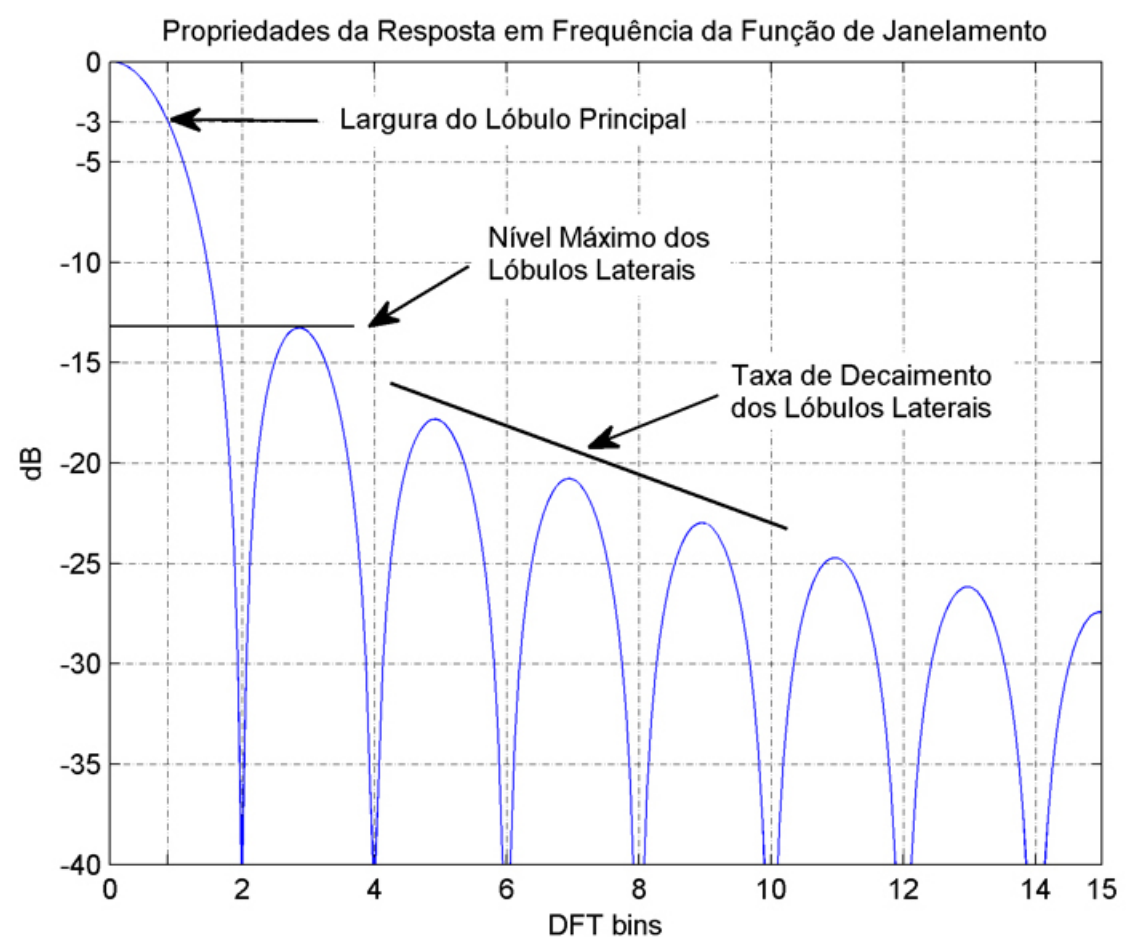

Figura 2.3: Resposta em frequência de uma janela retangular com as principais características ressaltadas pelas flechas. A flecha superior denota a largura do lóbulo principal como sendo o ponto onde a amplitude da resposta em frequência cai a $-3 \mathrm{~dB}$. A flecha intermediária aponta o nível máximo dos lóbulos laterais como sendo o ponto de máximo atingido pelo lóbulo adjacente ao pricipal e a flecha inferior ressalta a taxa de decaimento dos lóbulos laterais.

Slepian e Pollack (1961) pesquisaram a fundo em diversos artigos uma janela que, ao ser maximamente concentrada em $\omega=0$ no domínio da frequência, pudesse oferecer um bom balanço entre largura do lóbulo principal e área dos lóbulos laterais (Oppenheim et al., 1989). Os resultados eram baseados em funções de onda elipsóides esféricas, porém não práticas para resultados computacionais devido a alta complexidade de seu cálculo. Posteriormente Kaiser e Schafer (1980) encontraram uma janela quase-ótima formada através da função modificada de Bessel de ordem zero. A janela de Kaiser é então definida como

$$
w[n]= \begin{cases}\frac{I_{0}\left[\beta\left(1-[(n-\alpha) / \alpha]^{2}\right)^{1 / 2}\right]}{I_{0}(\beta)}, & 0 \leq n \leq M-1 \\ 0, & \text { c.c. }\end{cases}
$$

onde $\alpha=(M-1) / 2$ e $I_{0}(\cdot)$ representa a função modificada de Bessel de ordem zero (Oppenheim et al., 1989). Através do tamanho da janela $M$ e do valor de $\beta$ é possível balancear a janela de forma a se obter um bom equilíbrio entre a largura do lóbulo principal e a área dos 
Tabela 2.1: Comparação das Principais Característica de Diversas Funções de Janelamento

\begin{tabular}{lccc}
\hline Janelas & $\begin{array}{c}\text { Nível Máximo dos } \\
\text { Lóbulos Laterais }^{1}\end{array}$ & $\begin{array}{c}\text { Largura do } \\
\text { Lóbulo Principal }\end{array}$ & $\begin{array}{c}\text { Taxa de Decaimento dos } \\
\text { Lóbulos Laterais }^{1}\end{array}$ \\
\hline Retangular & $13,3 \mathrm{~dB}$ & $0,975 \Delta f$ & $20 \mathrm{~dB} / \mathrm{dec}$ \\
\hline Bartlett & $26,5 \mathrm{~dB}$ & $1,25 \Delta f$ & $40 \mathrm{~dB} / \mathrm{dec}$ \\
\hline Hann & $31,5 \mathrm{~dB}$ & $1,375 \Delta f$ & $60 \mathrm{~dB} / \mathrm{dec}$ \\
\hline Blackman & $58,1 \mathrm{~dB}$ & $1,625 \Delta f$ & $60 \mathrm{~dB} / \mathrm{dec}$ \\
\hline Kaiser $(\beta=4)$ & $30,1 \mathrm{~dB}$ & $1,125 \Delta f$ & $20 \mathrm{~dB} / \mathrm{dec}$ \\
\hline Kaiser $(\beta=9)$ & $66,4 \mathrm{~dB}$ & $1,625 \Delta f$ & $20 \mathrm{~dB} / \mathrm{dec}$ \\
\hline Flattop & $44 \mathrm{~dB}$ & $2,94 \Delta f$ & $20 \mathrm{~dB} / \mathrm{dec}$ \\
\hline
\end{tabular}

lóbulos laterais.

\subsection{O Periodograma de Welch}

A estimativa do espectro de potência de Welch (1967) é baseada no método de estimativa de periodograma desenvolvido por Bartllet. O método de Bartlett consiste em dividir uma sequência de $N$ pontos em $K$ segmentos, sendo então calculados os periodogramas de cada um dos $K$ segmentos. A estimativa do espectro de potência de Bartlett é então dada pela média dos periodogramas de cada um dos $K$ segmentos (Proakis e Manolakis, 1996). Com esse procedimento, a variância do espectro resultante é $K$ vezes menor do que do espectro calculado para a sequência original.

Welch alterou o periodograma de Bartlett introduzindo sobreposição aos segmentos e possibilitando o uso de uma janela em cada um dos segmentos da sequência original. Dada uma sequência $x[n]$ com $N$ pontos, cada um dos segmentos de Welch é descrito por

$$
\begin{array}{r}
x_{i}[m]=x[m+i D] \quad m=0,1, \ldots, M-1 \\
i=0,1, \ldots, L-1
\end{array}
$$

em que $i D$ é o ponto inicial do segmento em questão e $D$ é responsável pela sobreposição entre os segmentos. Se o valor de $D=M$ os segmentos não se sobrepõe, e se o valor de $D=M / 2$ então há 50\% de sobreposição entre os segmentos (Proakis e Manolakis, 1996).

A segunda mudança introduzida por Welch é a possibilidade de se utilizar uma janela diferente da retangular para a análise do periodograma, o resultado disso é o periodograma modi- 


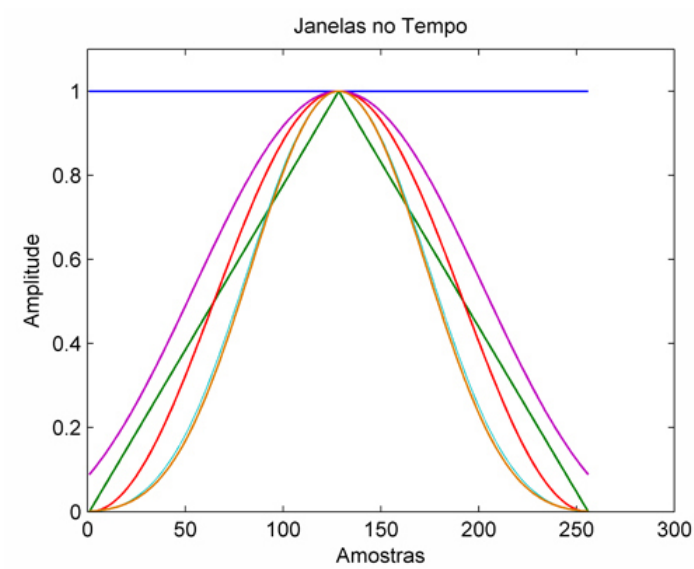

(a)

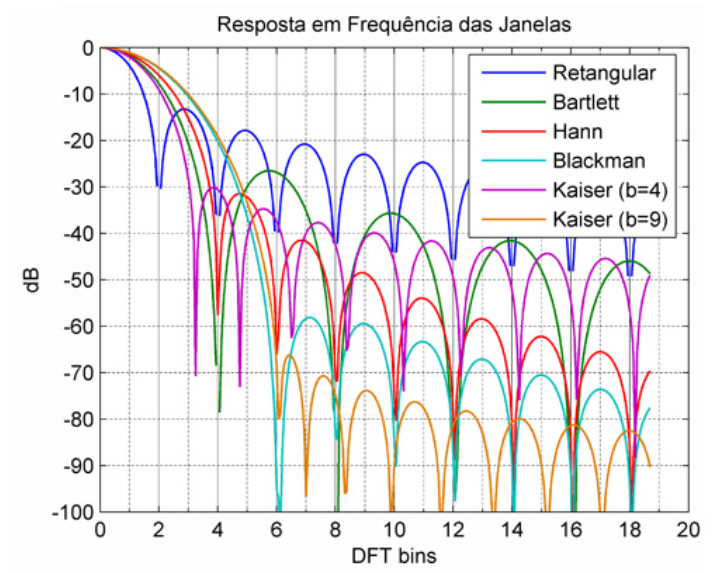

(b)

Figura 2.4: Comparação entre diversos tipos de janelas. (a) Janelas representadas no domínio do tempo (neste caso com 256 pontos). (b) Resposta em frequência das janelas representadas na figura (a)

ficado

$$
P_{x x}^{(i)}[k]=\frac{1}{M U}\left|\sum_{m=0}^{M-1} x_{i}(m) w(m) e^{\frac{-j 2 \pi k m}{M}}\right|^{2} \quad i=0,1, \ldots, L-1
$$

em que U é uma fator de normalização para a potência da função de janelamento (Proakis e Manolakis, 1996), onde

$$
U=\frac{1}{M} \sum_{m=0}^{M-1} w^{2}(m)
$$

O periodograma de Welch é então dado pela média dos periodogramas de cada um dos $i$ segmentos conforme descrito em

$$
P_{x x}^{W}[k]=\frac{1}{L} \sum_{i=0}^{L-1} P_{x x}^{(i)}[k]
$$

O método de Welch não altera o valor esperado do periodograma da sequência porém há uma redução significativa na variância do periodograma. Desta forma, ao considerar o conteúdo a ser analisado como sendo determinístico e o ruído presente na sequência como sendo um processo estocástico, há uma melhora na relação sinal-ruído do periodograma. 


\subsection{Short-Time Fourier Transform (Espectrograma)}

A ferramenta para determinação do espectro de potência de um sinal discreto discutida até agora, a DFT, parte do pressuposto de que a composição do sinal é a mesma do começo ao fim, ou seja, as mesmas frequências e ruídos que compõe uma parte do sinal está, na verdade, presente em todo o sinal sem alterar suas características de fase e amplitude.

No caso de sinais transitórios, a DFT por si só não é suficiente para descrever como o sinal varia com o tempo. É definida então a STFT (Short-Time Fourier Transform) como

$$
X[n, \omega)=\sum_{m=-\infty}^{\infty} x[n+m] w[m] e^{-j \omega m}
$$

em que $w[n]$ é a janela e $x[n]$ é o sinal. É importante notar que o sinal e a janela são discretos mas a frequência $\omega$ é uma variável contínua (Oppenheim et al., 1989).

A equação acima representa a transformada de Fourier de uma versão atrasada ou adiantada do sinal, $x[n+m]$, quando aplicada a uma função de janelamento $w[m]$. Desta forma, através de atrasos de tempo $n$ é possível observar o espectro em diferentes trechos do sinal.

Computacionalmente não é possível calcular valores para uma variável contínua, portanto, assim como a transformada de Fourier pode ser amostrada na frequência, a STFT também pode. Da mesma forma, também é possível apenas calcular computacionalmente a STFT de sinais finitos. Dado um sinal com $N$ amostras e uma janela $w[m]$ com $L$ amostras definida para $0 \leq m \leq L-1$, sendo $N \geq L$, a STFT desse sinal é dada por

$$
X[n, k]=X\left[n, \frac{2 \pi k}{L}\right]=\sum_{m=0}^{L-1} x[n+m] w[m] e^{-j(2 \pi / L) k m} \quad k=0,1, \ldots, L-1
$$

A Figura 2.5a exibe uma função chirp (um cosseno que tem sua frequência variando linearmente com o tempo) multiplicada por uma função exponencial de decaimento. Na Figura 2.5b observa-se o resultado da STFT do sinal da Figura 2.5a. Dessa forma pode-se através dessa análise concluir a evolução linear da frequêcia assim como sua variação de amplitude com o tempo. 


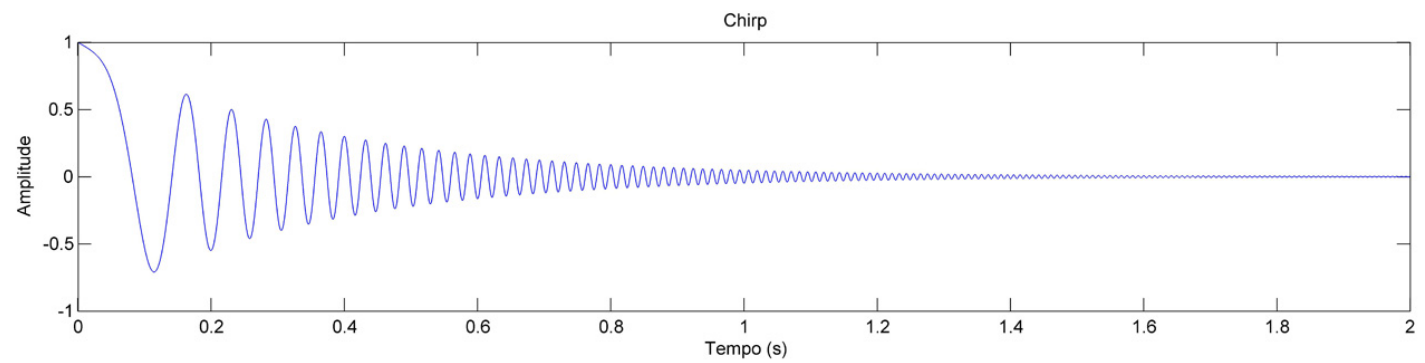

(a)

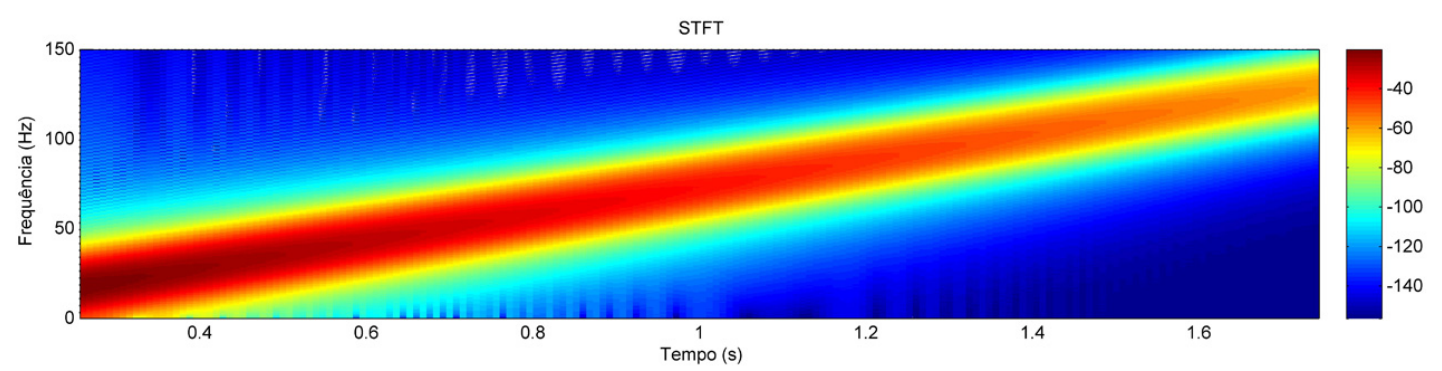

(b)

Figura 2.5: (a) Chirp representando um sinal gerado por uma função senoidal variando de $0 \mathrm{~Hz}$ a $150 \mathrm{~Hz}$ em 2 segundos multiplicada por uma função exponencial com expoente negativo. (b) STFT resultante da análise do sinal da figura (a), a intensidade é representada pela temperatura da cor.

\subsection{O Algoritmo de Levenberg-Marquardt para Ajuste Não-Linear}

O algoritmo desenvolvido por Levenberg (1944) e posteriormente melhorado por Marquardt (1963) é um método iterativo para a busca do mínimo de uma função com mais de uma variável expressa pela soma dos quadrados de funções reais não-lineares. O algoritmo de Levenberg-Marquardt (LMA) pode ser visto como uma combinação do método steepest descent e o método de Gauss-Newton (Sun e Yuan, 2006). Quando a proposição da solução inicial está longe da solução real ele se comporta como o método steepest descent, lento porém com convergência garantida. Caso a solução inicial seja uma boa suposição para a solução real o LMA se comporta como o método de Gauss-Newton.

Uma das principais aplicações do LMA é no ajuste de curvas não-lineares a vetores de amostras $\boldsymbol{x}$ e $\boldsymbol{y}$. Dado um modelo de função a ser ajustado $f\left(x_{k}\right) \operatorname{com}$ parâmetros $\boldsymbol{\beta}$, é definida uma função residual dada por

$$
r\left(x_{k}, \boldsymbol{\beta}\right)=y_{k}-f\left(x_{k}, \boldsymbol{\beta}\right)
$$


na qual $x_{k}$ é a $k$-ésima amostra de $x$ e $f\left(x_{k}, \boldsymbol{\beta}\right)$ é o valor da função $f\left(x_{k}\right)$ usando parâmetros $\boldsymbol{\beta}$. Determinado os parâmetros $\boldsymbol{\beta}$ para que a soma dos quadrados dos residuais $S(\boldsymbol{\beta})$, dada pela equação 2.33, seja mínima, a curva modelo está ajustada aos dados (Madsen et al., 2004),

$$
S(\boldsymbol{\beta})=\sum_{k=0}^{M-1} r\left(x_{k}, \boldsymbol{\beta}\right)^{2}
$$

na qual $M$ é o total de amostras nos vetores $\boldsymbol{x}$ e $\boldsymbol{y}$.

A cada iteração, o vetor de parâmetros $\boldsymbol{\beta}$ é atualizado com uma nova estimativa $\boldsymbol{\beta}+\delta$. No método de Gauss-Newton (Sun e Yuan, 2006) as atualização dos parâmetros, $\delta$, é encontrada através de

$$
\left(\mathbf{J}^{T} \mathbf{J}\right) \delta=\mathbf{J}^{T}[\mathbf{y}-\mathbf{f}(\boldsymbol{\beta})]
$$

em que $\boldsymbol{y}$ e $\boldsymbol{f}$ são vetores, nos quais a $k$-ésima linha possui valores $y_{k}$ e $f\left(x_{k}, \boldsymbol{\beta}\right)$ respectivamente, e $\boldsymbol{J}$ é a matrix Jacobiana onde cada linha representa o gradiente de $\boldsymbol{f}$ com relação aos parâmetros $\boldsymbol{\beta}$.

Levenberg (1944) contribui com a adição de um parâmetro de amortecimento que permite alternar entre os métodos de Gauss-Newton e o steepest descent. A atualização do parâmetro $\delta$ é então dada por

$$
\left(\mathbf{J}^{T} \mathbf{J}+\lambda \mathbf{I}\right) \delta=\mathbf{J}^{T}[\mathbf{y}-\mathbf{f}(\boldsymbol{\beta})]
$$

na qual $\lambda$ é o fator de amortecimento introduzido por Levenberg e $\boldsymbol{I}$ é a matriz identidade.

Posteriormente, Marquardt (1963) alterou a matriz identidade por uma matriz métrica $\boldsymbol{D}$ entre a grandeza da Hermitiana $\mathbf{J}^{T} \mathbf{J}$ e do fator de amortecimento $\lambda$. A matriz métrica $\boldsymbol{D}$ é dada pela diagonal da matriz Hermitiana. 


\section{Capítulo 3}

\section{Materiais e Métodos}

No capítulo 2 foram introduzidas as teorias relacionadas ao método de determinação do amortecimento por ressonância acústica. Neste capítulo serão apresentados os materiais utilizados para desenvolvimento e execução dos ensaios assim como os métodos utilizados para a determinação do amortecimento.

\subsection{Matlab}

MATLAB $\mathfrak{r}$ (abreviação de MATtrix LABoratory) é um software interativo e de alta performance destinado ao desenvolvimento de algoritmos, visualização de dados, análise de dados e cálculos numéricos (Mathworks, 2010). Usando o MATLAB é possível realizar tarefas complexas de forma muito mais simples do que seria realizar as mesmas implementações usando C, C++ ou Fortran.

O MATLAB foi utilizado neste trabalho por permitir fácil aquisição, manipulação, processamento e exibição dos dados associado com uma linguagem de programação simples e de alto-nível. A linguagem usada no MATLAB é conhecida como M-código ou simplesmente M.

Além das diversas funções nativas do MATLAB é possível adquirir bibliotecas (também conhecidas por toolboxes) que possuem funções de mais alto-nível realizando tarefas mais complexas. Devido as funções utilizadas para o desenvolvimento dos algoritmos deste trabalho, duas bibliotecas adicionais foram utilizadas. Um das bibliotecas específica para processamento de sinais e outra para otimização.

Data Acquisition Toolbox é uma biblioteca do MATLAB voltada para aquisição e síntese 
de sinais analógicos compatível com diversos hardwares de aquisição de sinais. Através do seu uso é possível fazer a leitura de sinais analógicos diretamente dentro do MATLAB, permitindo diversas configurações como frequência de amostragem, número de pontos a serem lidos e níveis de trigger configurados em hardware ou software para início da aquisição.

Essa biblioteca ainda permite que sinais sintetizados sejam enviados para hardwares de sintetização de sinais analógicos como placas de áudio.

A biblioteca Signal Processing Toolbox compreende uma série de algoritmos de processamento de sinais analógicos e digitais que são padrões da indústria (Mathworks, 2010). Além das funções disponíveis para uso a biblioteca ainda conta com interface gráfica para projeto de filtros entre outras ferramentas. A maior parte das funções possuem o código aberto para inspeção permitindo inclusive sua alteração caso se faça necessário.

Com o uso dessa biblioteca a filtragem, análise por transformadas, métodos de estimativa espectral paramétricos e não paramétricos tornam-se atividades mais simples e agilizam a implementação do algoritmo de processamento.

Similar ao conceito da biblioteca Signal Processing Toolbox, a Optimization Toolbox provê ao usuário algoritmos para solução de problemas de cálculo númerico lineares e não-lineares. Entre eles é possível encontrar algoritmos de programação linear, programação não-linear, solução de problemas de mínimos quadrados lineares e não-lineares entre outros.

Na seção 3.5, onde o algoritmo para cálculo do amortecimento é apresentado, pode-se observar a necessidade do uso dessas bibliotecas e de seus algoritmos.

A versão do MATLAB usada neste trabalho é o MATLAB R2009a.

\subsection{Aquisição do Sinal}

A aquisição do sinal é uma importante etapa do desenvolvimento do algoritmo para a determinação do amortecimento. Com isso é possível aprimorar e verificar o funcionamento do algoritmo baseado em testes usando sinais reais originados da ressonância de materiais, não limitando-se a sinais simulados.

O sistema de aquisição utilizado é composto por um microfone com cápsula cardióide Behringer B-5 e uma placa de áudio USB M-audio Fast Track Ultra ligada a um computador rodando o MATLAB. As características do microfone e da placa de aquisição podem ser 
encontradas a seguir.

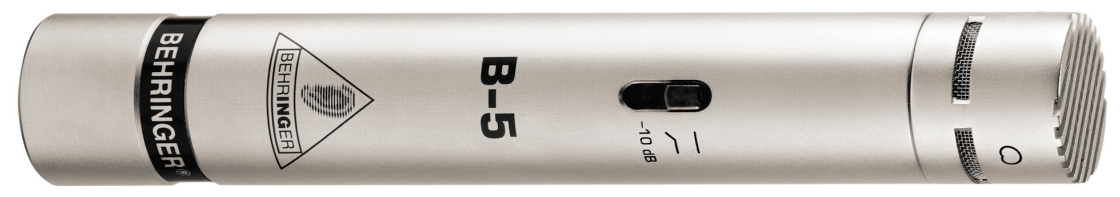

Figura 3.1: Microfone Behringer B-5 com condensador capacitivo e cápsula cardióide usado para aferir o sinal de ressonância.

O microfone Behringer B-5 ${ }^{1}$, observado na Figura 3.1, é um microfone com condensador capacitivo acompanhado de uma cápsula cardióide. A resposta em frequência do microfone possui ganho unitário em sua banda de passagem entre $20 \mathrm{~Hz}$ e $20 \mathrm{kHz}$.

O microfone ainda conta com um filtro passa-baixas com frequência de corte em $150 \mathrm{~Hz}$ e atenuação de $6 \mathrm{~dB} /$ oitava. Segundo o manual do fabricante a relação sinal-ruído característica é de $78 \mathrm{~dB}$.

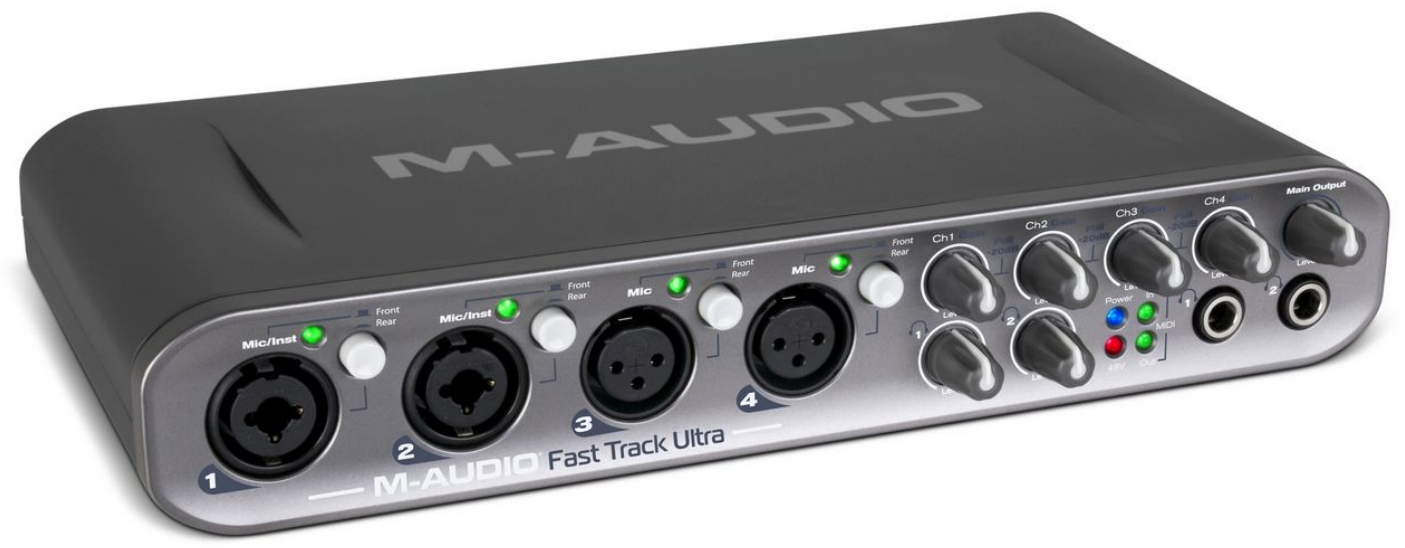

Figura 3.2: M-audio Fast Track Ultra utilizado para a aquisição de sinal via USB. Imagem retirada de http://www.assessoriatecnica.com.br.

A placa de aquisição de sinal M-audio Fast Track Ultra² ${ }^{2}$ com conexão USB, Figura 3.2, possui 4 canais de entrada, pré-amplificação de $48 \mathrm{~V}$ para o microfone com ganho de entrada de até $60 \mathrm{~dB}$ e saídas digitais e analógicas.

A aquisição pode ser configurada em até 96 ksps com 24 bits de resolução. A banda de

\footnotetext{
${ }^{1} \mathrm{http}: / /$ www.behringer.com

${ }^{2}$ http://www.m-audio.com
} 
passagem possui atenuação máxima de +/- 0,1dB e uma relação sinal-ruído de $96 \mathrm{~dB}$.

\subsection{Materiais para Análise}

Neste trabalho foram utilizadas um total de sete amostras diferentes para ensaios de cálculo de amortecimento, uma amostra de alumina densa $\left(\mathrm{Al}_{2} \mathrm{O}_{3}\right)$, duas amostras de concreto refratário de alta alumina com baixo teor de agregados, duas amostras de concreto refratário de alta alumina com alto teor de agregados e duas amostras de concreto refratário silico-aluminoso impregnadas com coque resultante do processo de craqueamento de petróleo. A Tabela 3.1 sintetiza as características de cada amostra, ciclos de choque térmico sofridos e severidade do choque térmico.

Tabela 3.1: Resumo das amostras utilizadas no ensaios de amortecimento

\begin{tabular}{llccc}
\hline Amostra & Descrição & Amostra Irmã & $\begin{array}{c}\text { Ciclos de } \\
\text { Choque } \\
\text { Térmico }\end{array}$ & $\begin{array}{c}\text { Temperatura } \\
\text { do Choque } \\
\text { Térmico }\end{array}$ \\
\hline 1 & Alumina densa $\left(\mathrm{Al}_{2} \mathrm{O}_{3}\right)$ & - & 0 & - \\
\hline 2 & $\begin{array}{l}\text { Concreto refratário de alta } \\
\text { alumina com baixo teor de } \\
\text { agregados }\end{array}$ & 3 & 0 & - \\
\hline 3 & $\begin{array}{l}\text { Concreto refratário de alta } \\
\text { alumina com baixo teor de } \\
\text { agregados }\end{array}$ & 2 & 1 & $1000^{\circ} \mathrm{C}$ \\
\hline 4 & $\begin{array}{l}\text { Concreto refratário de alta } \\
\text { alumina com alto teor de } \\
\text { agregados }\end{array}$ & 5 & 0 & - \\
\hline 5 & $\begin{array}{l}\text { Concreto refratário de alta } \\
\text { alumina com alto teor de } \\
\text { agregados }\end{array}$ & 4 & 2 & $1000^{\circ} \mathrm{C}$ \\
\hline 6 & $\begin{array}{l}\text { Concreto refratário } \\
\text { silico-aluminoso } \\
\text { impregnado com coque }\end{array}$ & 7 & & \\
\hline 7 & $\begin{array}{l}\text { Concreto refratário } \\
\text { silico-aluminoso } \\
\text { impregnado com coque }\end{array}$ & 6 & & \\
\hline
\end{tabular}

Amostras irmãs representam amostras de um mesmo lote de fabricação e oriundas da mesma matéria-prima. Os ciclos de choque térmico são aplicados aquecendo-se a amostra até a temperatura descrita na tabela e então resfriando-a rapidamente em água a temperatura 
ambiente.

A amostra de alumina é um bom exemplo de material com ressonância regular. Por sua vez, as amostras de concreto refratário de alta alumina exemplificam uma aplicação em potencial: a utilização do amortecimento para caracterização do dano de concretos refratários. A Figura 3.3 mostra as amostras 1 (A), 2 (C) e 3 (B).

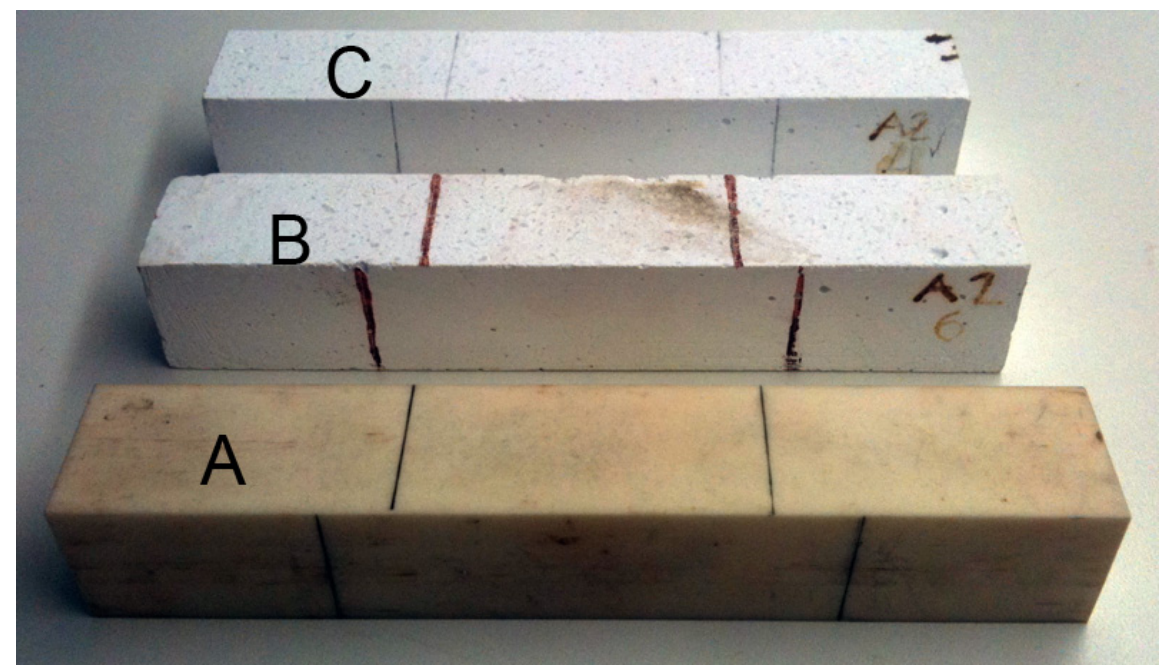

Figura 3.3: Amostras testadas para determinação do amortecimento. (A) Amostra de alumina densa, (B) amostra de concreto refratário comercial de alta alumina com danos por choque térmico e (C) amostra de concreto refratário comercial de alta alumina sem danos por choque térmico.

Apesar de não haver nenhuma relação direta entre o tamanho e formato das amostras com o amortecimento, as amostras utilizadas neste trabalho são padronizadas, sendo barras paralepipedais com $150 \mathrm{~mm}$ de comprimento e secção quadrada de $25 \mathrm{~mm}$ por $25 \mathrm{~mm}$ conforme desenho na Figura 3.4.

$150 \mathrm{~mm}$

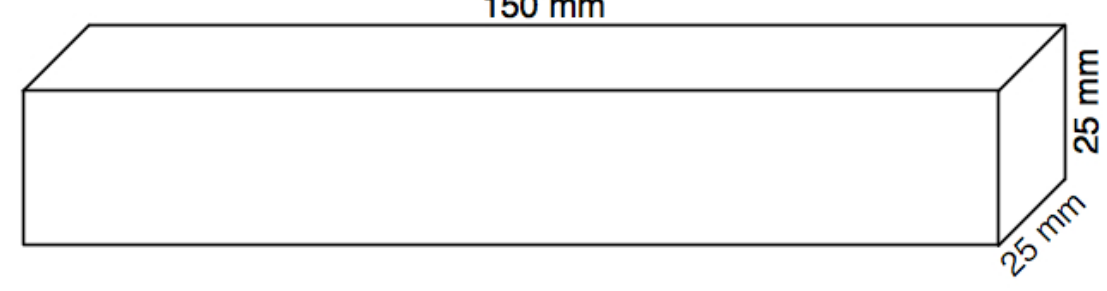

Figura 3.4: Formato padrão das amostras ensaiadas. 


\subsection{Suporte e Excitação do Material em Análise}

O apoio do material a ser testado quanto ao seu amortecimento é um item crítico no ensaio. Segundo ASTM (1995); Lord e Morrell (2006) no guia de boas práticas da NPL (National Physical Laboratory) para que não haja influência do apoio no ensaio, a peça deve ser apoiada sobre os nós de vibração (pontos que possuem as menores amplitudes de vibração) do modo a ser analisado.

Dada uma barra de secção retangular com comprimento $L$, os nós de vibração do modo flexural fundamental, são secções posicionadas em 0,223 $\cdot L$ e 0, $777 \cdot L$ (ASTM, 1995; Lord e Morrell, 2006).

Com esse objetivo, para suporte e posicionamento da peça foi utilizado uma base da ATCP Engenharia Física ${ }^{3}$ modelo Sonelastic RTS-Auto (Figura 3.5a). Através de um sistema mecânico, a base posiciona automaticamente a barra a ser ensaiada baseando-se no seu comprimento, suspendendo-a pelos seus nós de vibração do modo flexural fundamental.

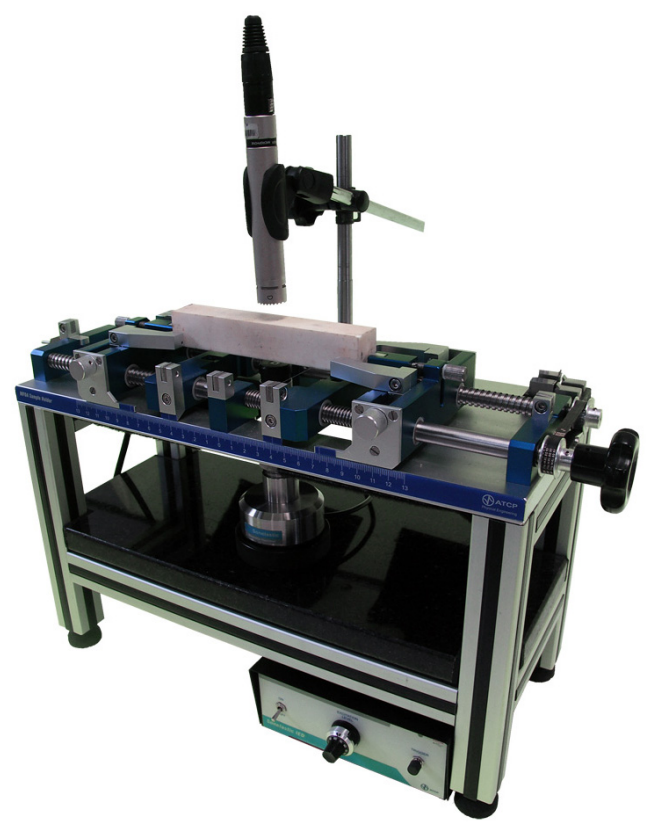

(a)

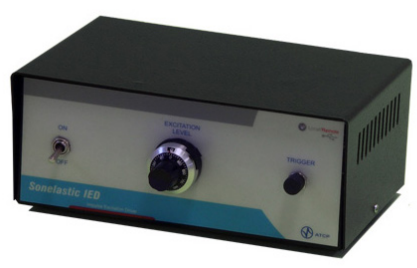

(b)

Figura 3.5: (a) Suporte de precisão com ajuste automático para corpos de prova. Permite testes com condições de contorno para o modo flexural e longitudinal ou para o modo torcional. (b) Sonelastic IED (esquerda) e atuador mecânico (direita).

\footnotetext{
${ }^{3}$ http://www.atcp.com.br
} 
A excitação do material é feita através do impacto de um pino metálico em um anti-nó de vibração da amostra (ponto com a maior amplitude de vibração do modo ensaiado). $\mathrm{O}$ equipamento utilizado para a excitação é o Sonelastic IED 4 exibido na Figura 3.5b, um sistema composto por um circuito eletrônico que pode ser comandado por USB e um solenóide tubular que impulsiona o pino metálico contra a amostra.

O pino metálico possui dureza suficiente para que o tempo de contato do pino com a amostra seja breve, de modo que o impacto se aproxime de um impulso (função delta de Dirac), excitando uniformemente frequências em uma largura de banda ampla (Oppenheim et al., 1989).

\subsection{Método de Cálculo do Amortecimento}

O algoritmo de determinação do amortecimento, implementado no MATLAB, pode ser dividido em três partes principais: aquisição do sinal, pré-processamento e cálculo do amortecimento.

A aquisição do sinal é feita através da Data Acquisition Toolbox, Seção 3.1, sendo que a origem dos dados é configurada como sendo a placa de aquisição M-Audio Fast Track Ultra. O fluxograma da aquisição pode ser observado na Figura 3.6.

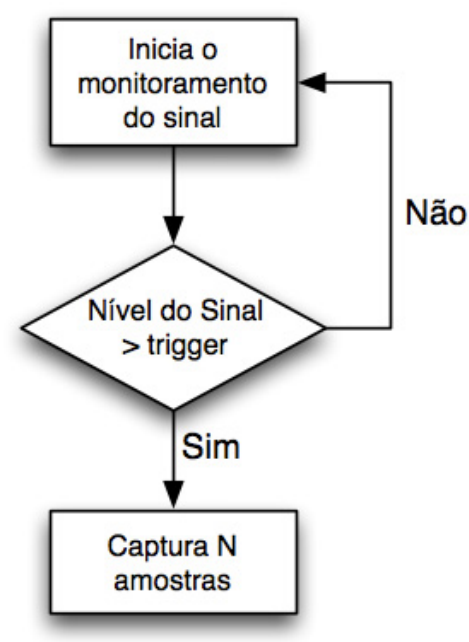

Figura 3.6: Fluxograma da aquisição de sinal como o algoritmo implementado no MATLAB.

A Data Acquisition Toolbox permite diversas configurações como a frequência de amostra-

\footnotetext{
${ }^{4}$ ATCP Engenharia Física - http://www.atcp.com.br
} 
gem, número de pontos a ser capturados e nível de trigger para que a aquisição se inicie.

Para esse processamento a frequência de amostragem está configurada para $96 \mathrm{ksps}$, taxa de aquisição do sistema M-audio, Seção 3.2, e suficiente para ser superior a frequência de Nyquist para a ressonância dos materiais propostos (Oppenheim et al., 1989). São capturados pontos suficientes para que a aquisição do sinal de ressonância seja completa, desde o início do sinal até que o mesmo tenha se atenuado e haja apenas a presença de ruído.

Após a captura do sinal, este é processado de forma a se detectar as suas ressonâncias e gerar a matriz de tempo-frequência. A sequência do algoritmo pode ser vista no fluxograma da Figura 3.7.

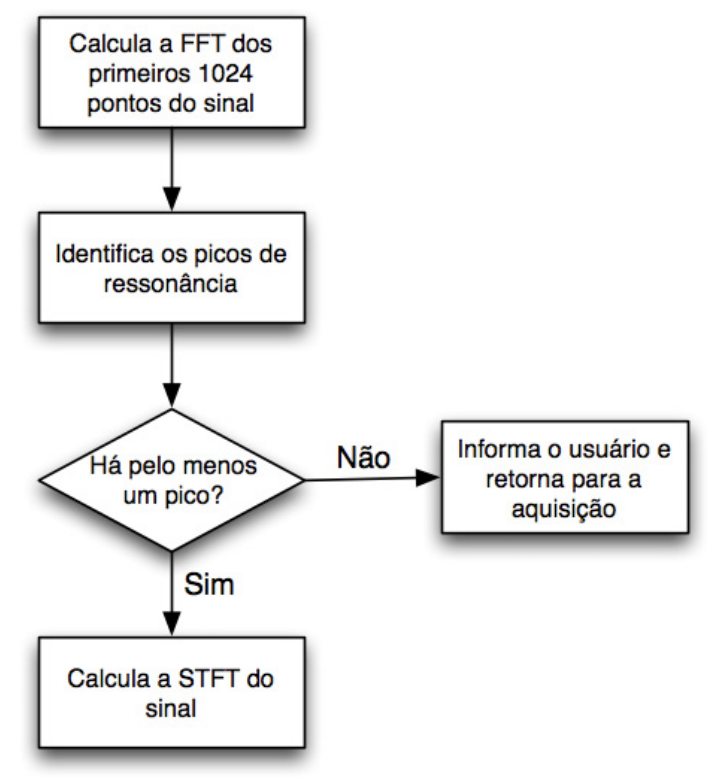

Figura 3.7: Fluxograma do pré-processamento em uma sequência estruturada.

O fluxograma da Figura 3.7 apresenta uma versão estruturada do processamento realizado, porém o MATLAB otimiza os ciclos de processamento através de sua capacidade de trabalhar facilmente com vetores e matrizes.

Primeiramente é calculada a DFT (através da FFT) dos primeiros 1024 pontos do sinal. Esse processamento é feito apenas no início do sinal de forma que a transformada de Fourier seja feita sobre um sinal com características mais próximas da estacionariedade (momentos estatísticos invariáveis entre subtrechos, Oppenheim et al. (1989)) e por ser a faixa em que todas as ressonâncias possuem a maior potência. 
Sobre o resultado da FFT é executada uma análise de nível de potência média do espectro, equação (3.1), e da derivada média da potência, equação (3.2), no espectro de magnitudes, de forma a se identificar como ressonância picos que tenham em sua rampa de subida ou descida um valor de derivada maior que duas vezes o valor da média da derivada $D_{a v g}$ e potência máxima de pico maior que duas vezes o nível médio do ruído $N_{\text {avg }}$.

$$
\begin{gathered}
N_{\text {avg }}=\frac{1}{L} \sum_{i=1}^{L} X[i] \\
D_{\text {avg }}=\frac{1}{L} \sum_{i=2}^{L}|X[i]-X[i-1]|
\end{gathered}
$$

Se houver picos de ressonância identificados é então calculada a matriz de tempo-frequência sobre todo os pontos do sinal. O cálculo dessa matriz é feito conforme descrito na Seção 2.5. Inicialmente, cada segmento usado no cálculo da STFT tinha seu espectro determinado por um periodograma de Welch, porém isso acarretava numa perda de resolução na frequência ou menor resolução temporal devido ao tamanho da janela. Optou-se por não usar o periodograma de Welch e calcular apenas a FFT de cada segmento para obter um ganho de resolução.

Para cada pico de ressonância identificado deve-se tentar determinar seu amortecimento através do ajuste de um modelo ao vetor da matriz de STFT que representa a evolução da potência da frequência em relação ao tempo.

O modelo que deve ser usado para esse ajuste é descrito pela Equação 2.12 e os parâmetros livres a serem determinados pelo ajuste são: $A_{0}, \tau$ e $A_{n}$.

O fluxograma desse método é exibido de forma estruturada na Figura 3.8, porém mais uma vez, devido as otimizações possíveis com o Matlab, os ciclos não estão presentes no algoritmo.

Devido a não linearidade dos parâmetros do modelo da Equação 2.12, o método de ajuste adotado é o Levemberg-Marquardt, como descrito na Seção 2.6, sendo este um procedimento iterativo de ajuste por mínimos quadrados.

Sendo possível o ajuste dos parâmetros $A_{0}, \tau$ e $A_{n}$ (convergência do método de LevembergMarquardt), as Equações (2.13) e (2.11), associadas ao valor do parâmetro $\tau$ e da frequência de ressonância amortecida $\omega_{d}$, encontrada como pico de ressonância no espectro de magnitudes, são usadas na determinação do valor do amortecimento $\zeta$ em si. 


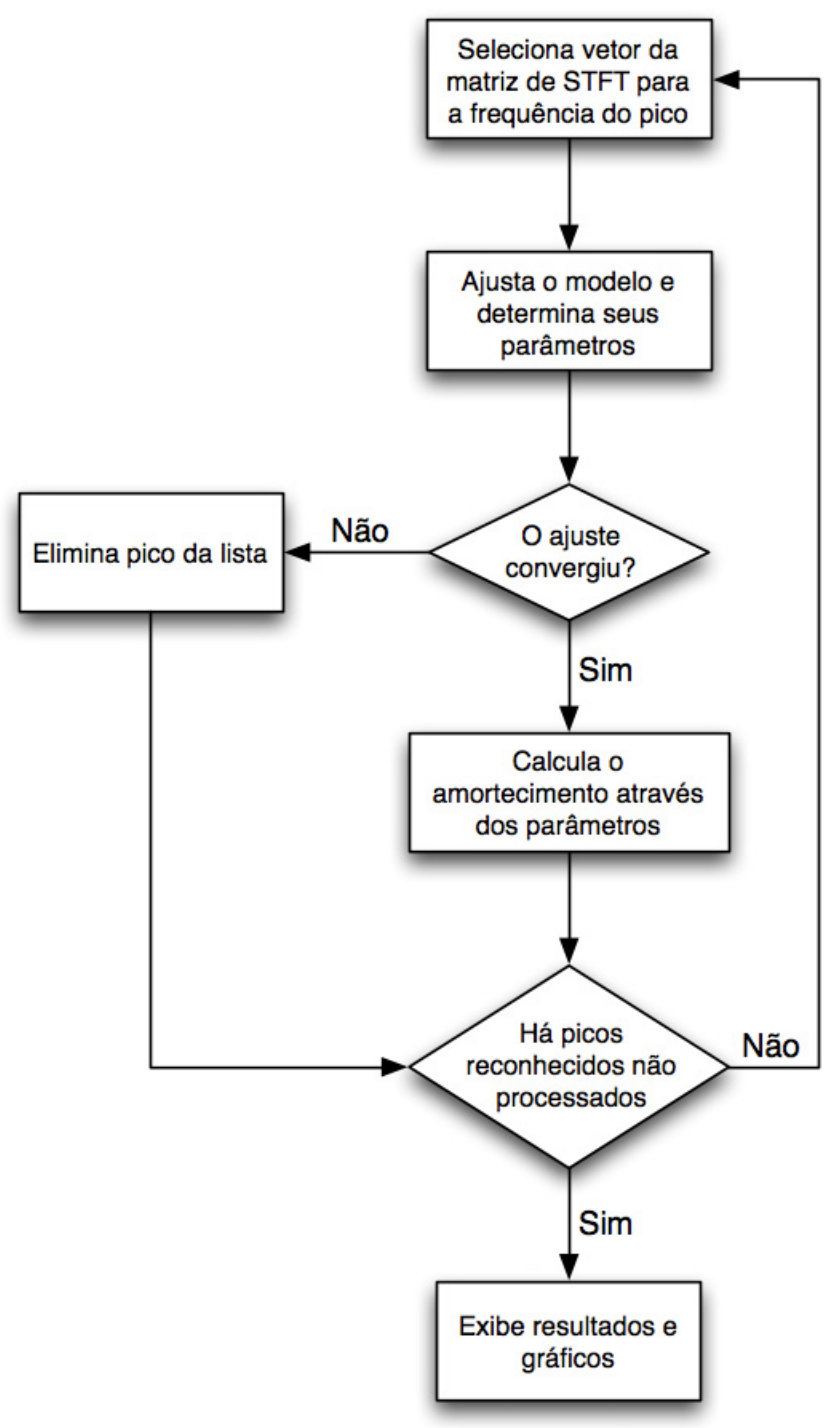

Figura 3.8: Fluxograma da versão estruturada do algoritmo para determinação do amortecimento. 


\section{Capítulo 4}

\section{Resultados}

Este capítulo tem dois objetivos, validar o método de cálculo através de simulações e mostrar resultados reais obtidos a partir do ensaio de quatro diferentes tipos de materiais. O ensaio dos materiais demonstra o potencial de aplicação do método para análise de materiais, em particular concretos refratários de alta alumina.

\subsection{Validação do Método de Cálculo}

O método foi desenvolvido com o objetivo de determinar o amortecimento de ressonâncias de materiais. A fim de validar o funcionamento do método foi gerado um sinal simulado descrito pela ressonância de um sistema massa-mola-amortecedor de um grau de liberdade, modelo que descreve uma ressonância de um material (De Silva, 2007). Este sinal foi analisado pelo algoritmo de cálculo e o resultado obtido foi comparado com os parâmetros usados para criação do sinal.

O modelo viscoelástico utilizado tem sua amplitude de vibração descrita pela equação (2.10) e a tabela 4.1 descreve os valores utilizados como parâmetros no modelo. A equação (2.10) tem sua versão discreta (amostrada com frequência $F s=96 k s p s$ ) dada por

$$
x(n)=A_{0} \cdot e^{-\zeta \Omega_{n} n T s} \cdot \cos \left(\Omega_{d} n T s+\phi\right) \text { para } 0 \leq n \leq N_{s}-1
$$

onde $T s=1 / F s$ e $N s=262144$ é o número total de pontos.

Para tornar o sinal simulado mais próximo do real, o sinal $x(n)$ é somado a um ruído 
Tabela 4.1: Parâmetros utilizados para a simulação de um sinal de ressonância através do uso de um modelo viscoelástico

\begin{tabular}{lcc}
\hline Parâmetro & Descrição & Valor utilizado \\
\hline$A_{0}$ & Amplitude inicial da vibração & $0.7 \mathrm{~V}$ \\
\hline$\zeta$ & Amortecimento viscoso & $2 \cdot 10^{-4}$ \\
\hline$\Omega_{n}$ & Frequência de ressonância & $2 * \pi * 4000 \mathrm{rad} / \mathrm{s}$ \\
\hline
\end{tabular}

branco gaussiano com média nula e valor RMS tal que a relação sinal-ruído média em todo o sinal fosse de 30dB. Este sinal pode ser observado na Figura 4.1. A Figura 4.2 representa a Transformada Discreta de Fourier dos primeiros 1024 pontos do sinal simulado.

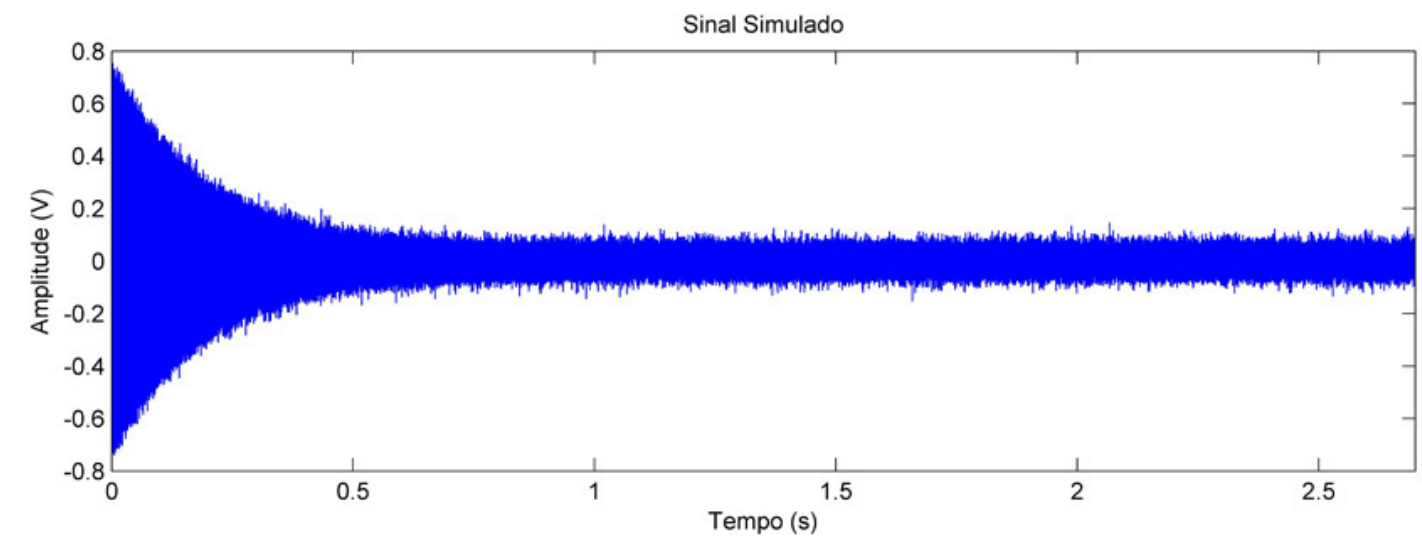

Figura 4.1: Variação de amplitude com o tempo do sinal simulado gerado a partir do modelo viscoelástico de ressonância somado a um ruído branco gaussiano com relação sinal-ruído média de $30 \mathrm{~dB}$.

A partir do sinal simulado foi executado o método proposto para o cálculo do amortecimento, o programa implementado no MATLAB foi executado e o resultado obtido pode ser observado na Figura 4.3, que representa a variação da potência para a frequência encontrada como sendo o modo de vibração simulado no sinal. A frequência encontrada tem o valor exato do valor de frequência aplicado no modelo. O amortecimento encontrado, também representado na imagem, tem um valor muito próximo do parâmetro de amortecimento usado no modelo, mostrando que a partir deste método é possível recuperar o valor de amortecimento a partir do algoritmo proposto.

Apenas por efeito ilustrativo, dado que não se pode assumir que o erro seja constante, a diferença entre o valor calculado do amortecimento e o que realmente foi usado é de $0,05 \%$.

O resultado da Short-Time Fourier Transform que contém a evolução de todas as frequên- 


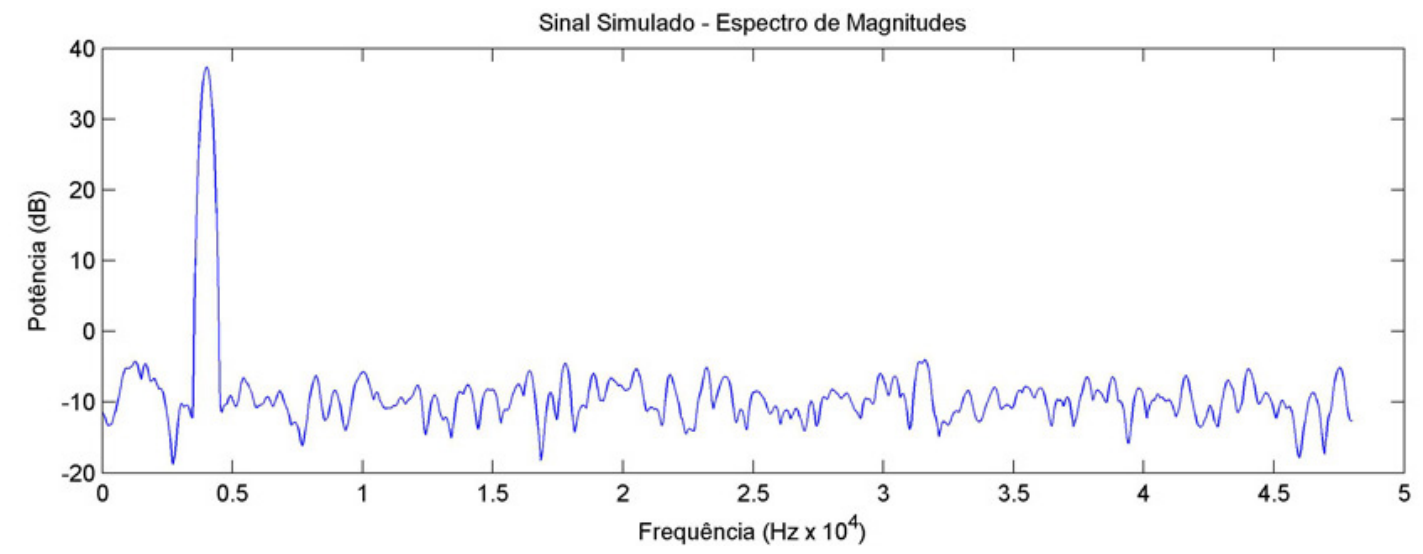

Figura 4.2: Espectro de magnitude dos primeiros 1024 pontos do sinal simulado representado na Figura 4.1.

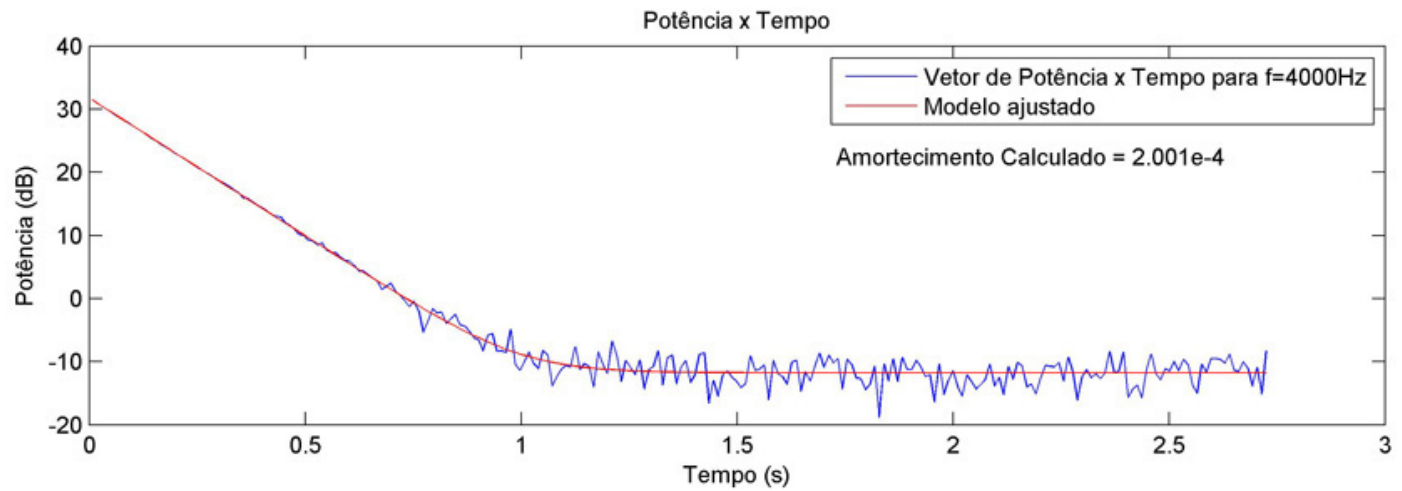

Figura 4.3: Variação de potência da frequência em função do tempo amostrado calculada como sendo a ressonância contida no sinal. A frequência encontrada é de $4 \mathrm{kHz}$ e o amortecimento calculado através do método é de $2.001 \cdot 10^{-4}$.

cias discretas do sinal simulado pode ser observado na Figura 4.4. Inicialmente vermelho, destacando a alta amplitude da frequência no início da oscilação, pode-se observar a frequência de ressonância simulada e é este vetor o exibido na Figura 4.3 que foi usado para o cálculo do amortecimento através do ajuste do modelo pelo método de cálculo.

\subsection{Aplicação para a Barra de Alumina}

Com o funcionamento do método validado, o algoritmo foi aplicado a um sinal real oriundo de uma barra descrita na seção Materiais e Métodos. A aquisição do sinal foi feita no próprio algoritmo de cálculo com um número de pontos predefinidos, neste caso, $262144\left(2^{18}\right)$ pontos. 


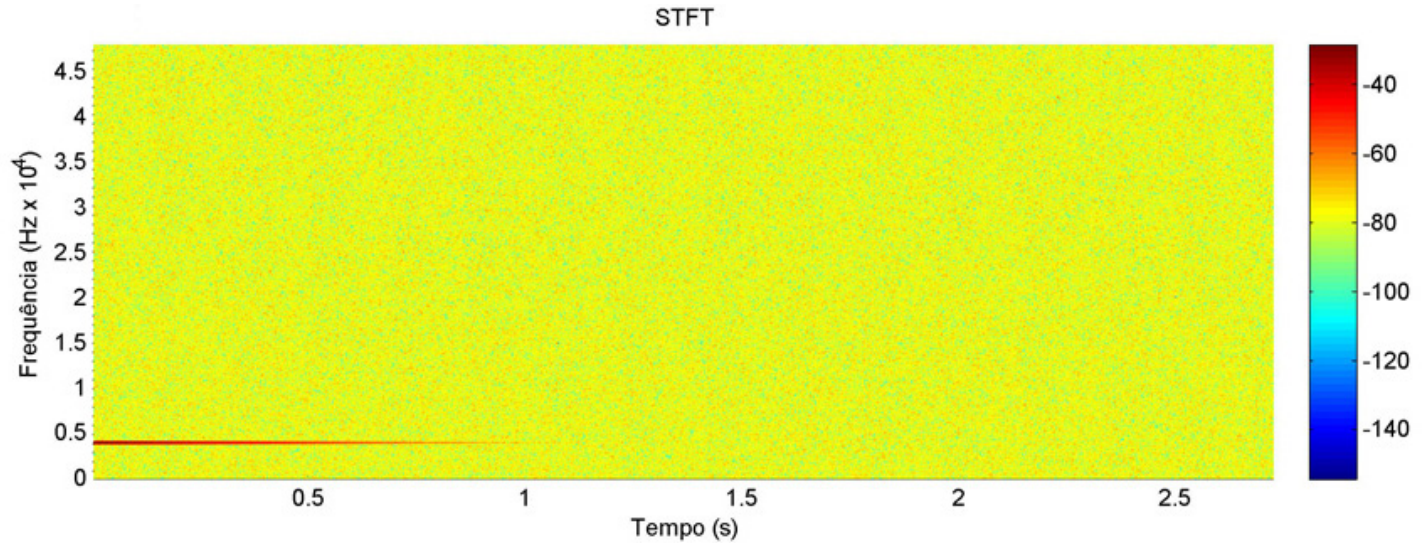

Figura 4.4: Short-Time Fourier Transform do sinal gerado pela simulação do modelo viscoelástico de ressonância. As cores representando a amplitude do sinal conforme exibido na caixa ao lado do gráfico.

O sinal obtido pela aquisição pode ser observado na Figura 4.5.

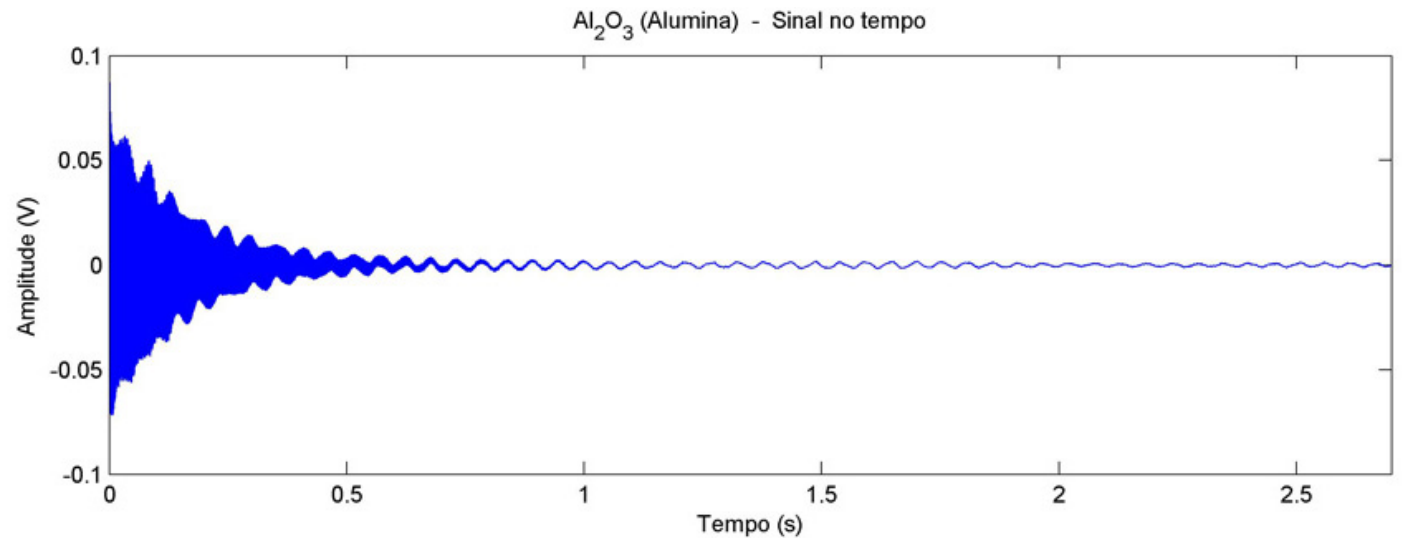

Figura 4.5: Sinal originário do impacto gerado pelo Sonelastic IED na barra de alumina e adquirido através da placa do microfone Behringer B-5 e da placa de aquisição M-Audio Fast Track Ultra.

A Figura 4.6 representa o espectro de magnitudes calculado para os primeiros 1024 pontos do sinal da Figura 4.5. Nessa, é possível observar com clareza o pico de ressonância do modo de vibração excitado, neste caso o flexural fundamental, devido ao posicionamento da barra, pontos de suporte, ponto de impacto e ponto de aquisição.

A evolução da potência com o tempo, dessa ressonância, pode ser observada na Figura 4.7. É também possível observar na imagem a frequência da ressonância assim como o valor do amortecimento calculado através do ajuste do modelo sobre os dados da curva. 


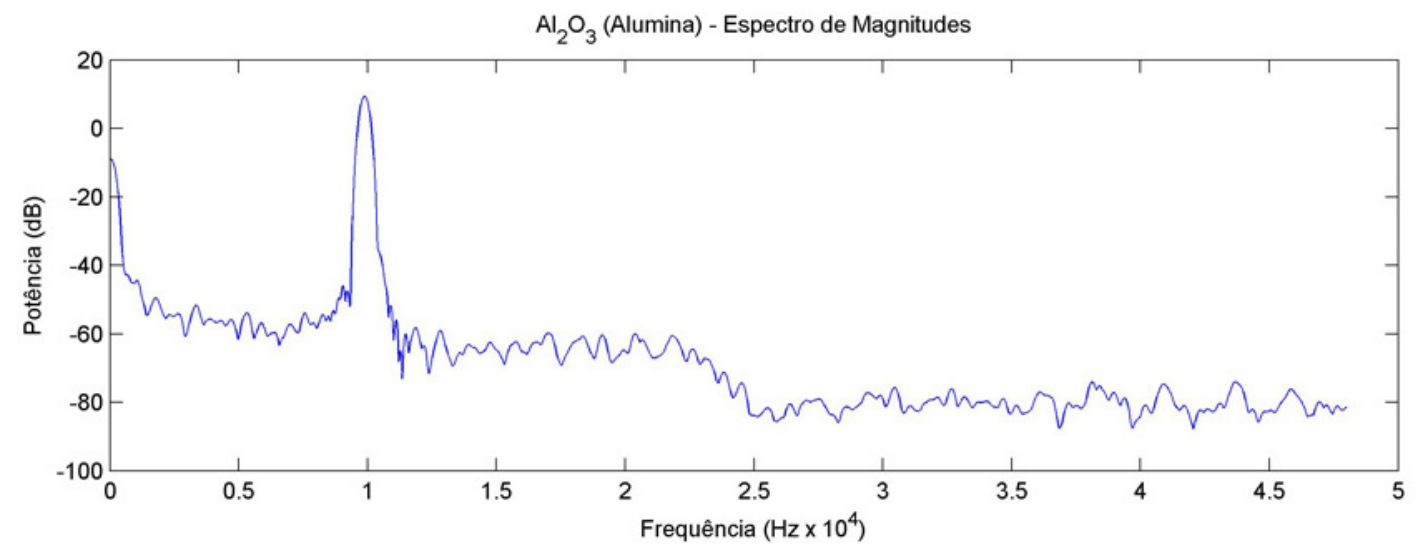

Figura 4.6: Espectro de magnitudes calculado para os primeiros 1024 pontos do sinal de ressonância da barra de alumina.

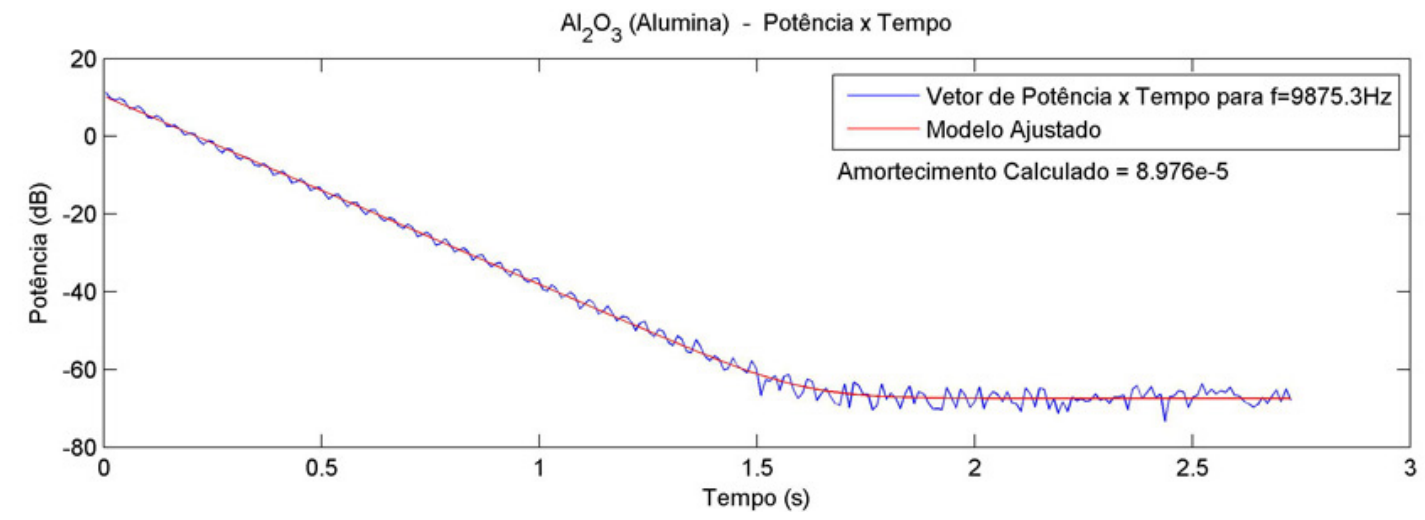

Figura 4.7: Evolução da potência com o tempo amostrado da frequência 9875,3 Hz e o amortecimento calculado através do ajuste do modelo (curva em vermelho).

\subsection{Aplicação para os Concretos Refratários}

As barras de concreto refratário comercial de alta alumina, principalmente a barra que sofreu dano por choque térmico, possuem uma ressonância mais complexa do que a ressonância da alumina devido a maior anisotropia daquelas.

O ensaio não-destrutivo de amostras de concreto refratário é de grande interesse na industria de materiais. Associado aos módulos elásticos, o amortecimento tem grande potencial para melhorar a compreensão de como reage a microestrutura dos concretos com diferentes graduações de dano. 


\subsubsection{Refratário de Alta Alumina com Baixo Teor de Agregados}

A Figura 4.8 mostra o sinal como foi amostrado em função do tempo para as duas amostras, com e sem dano por choque-térmico. Associada aos sinais da Figura 4.8, a Figura 4.9 mostra os espectros de magnitude das amostras.

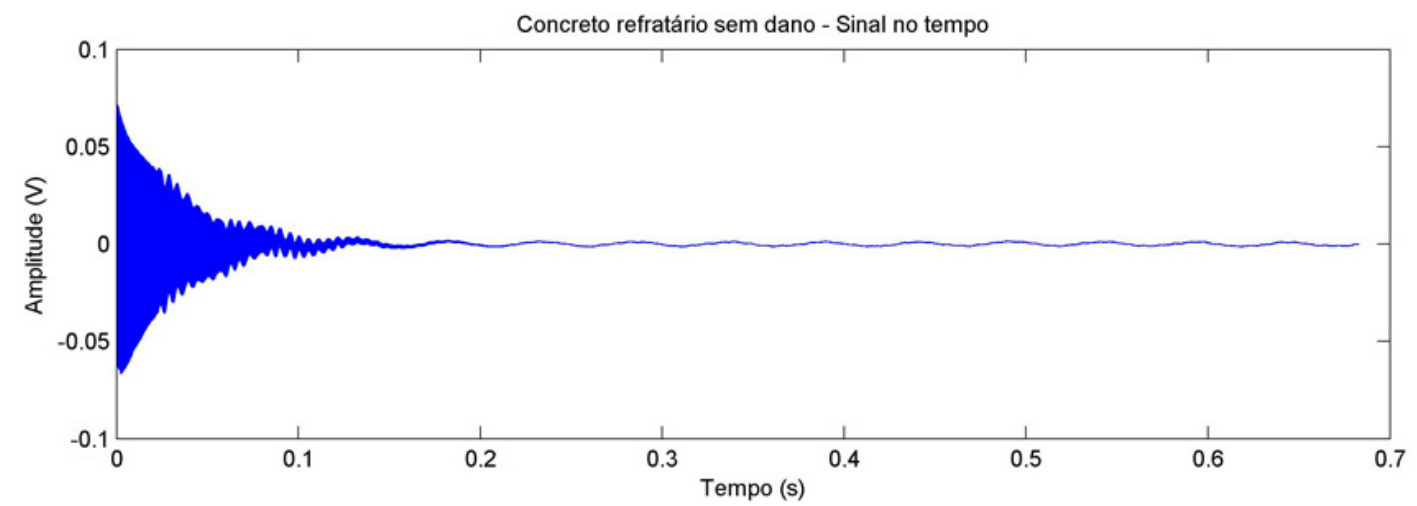

(a)

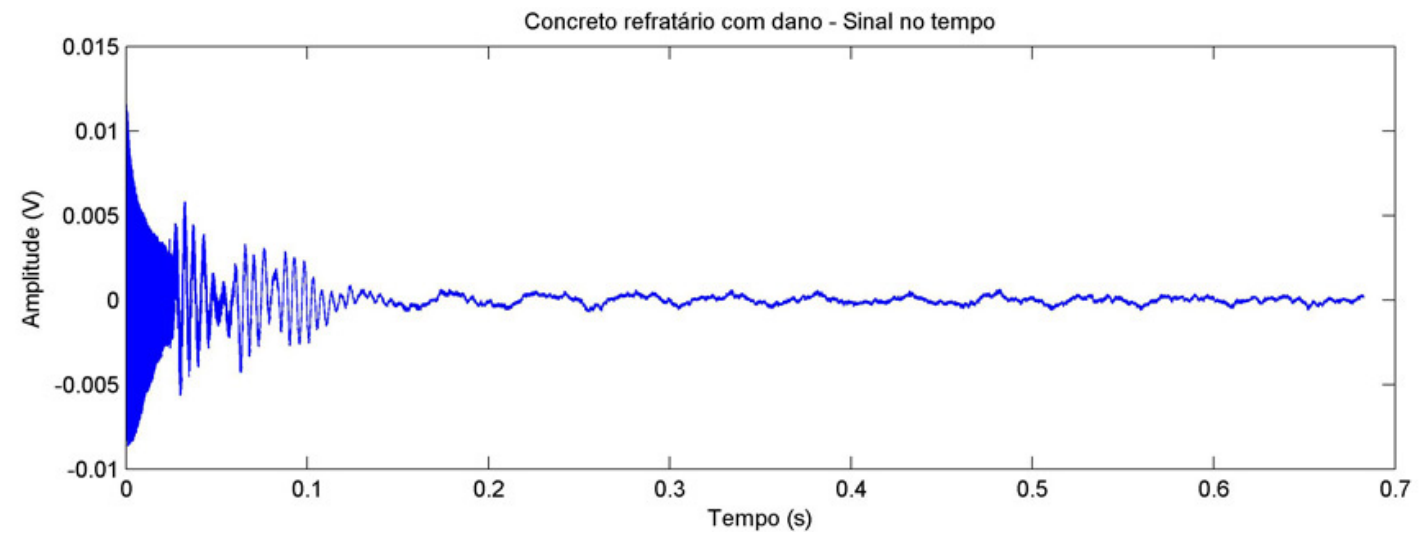

(b)

Figura 4.8: Sinais amostrados da amplitude de vibração pelo tempo de amostragem. (a) Sinal da amostra de concreto refratário com baixo teor de agregados (amostra 2) sem dano. (b) Sinal da amostra de concreto refratário com baixo teor de agregados (amostra 3) com dano por choque térmico. 


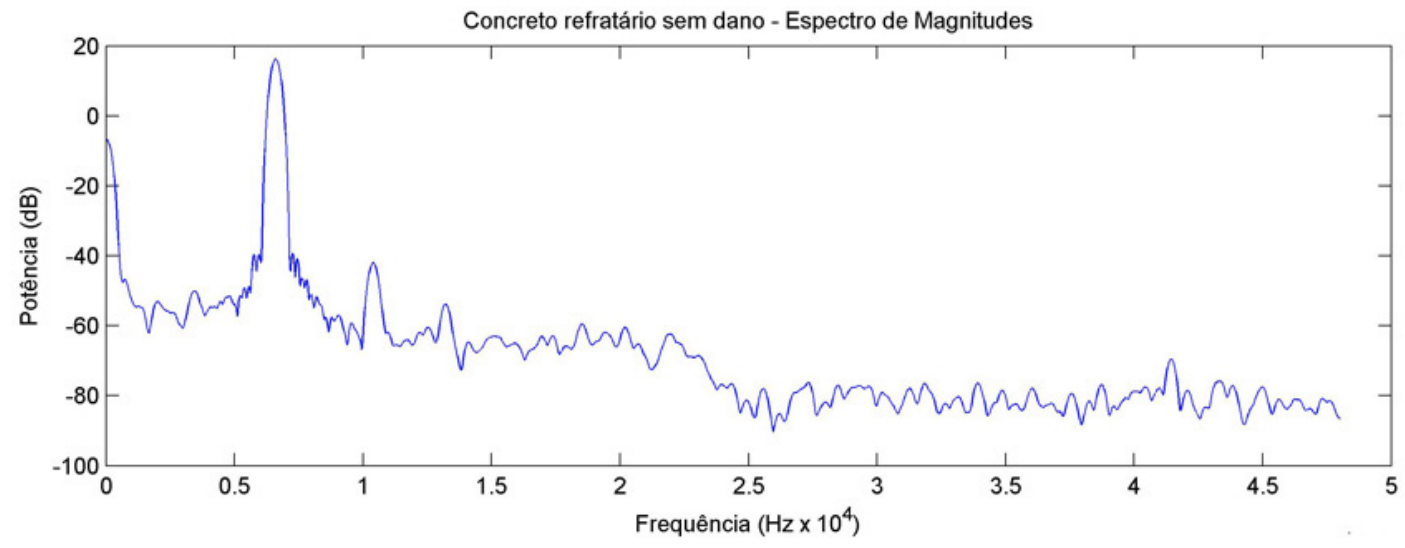

(a)

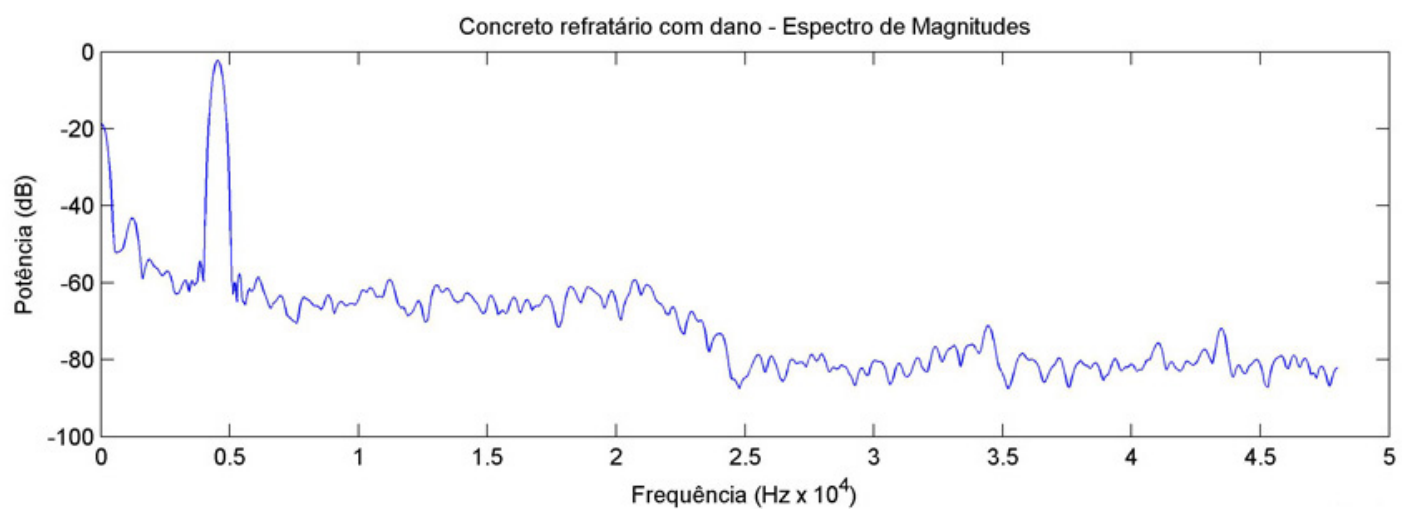

(b)

Figura 4.9: Espectros de magnitude dos primeiros 1024 pontos dos sinais representados na Figura 4.8. (a) Espectro de magnitude da amostra de concreto refratário com baixo teor de agregados (amostra 2) sem dano. (b) Espectro de magnitude da amostra de concreto refratário com baixo teor de agregados (amostra 3) com dano por choque térmico.

Observe que há um grande desvio entre as frequências de ressonância dos concretos com e sem dano. Isso se deve a alteração que ocorre ao módulo Young (Truesdell, 1960) ocasionada pelo dano estrutural sofrido pelo material que passou pelo ciclo de choque-térmico (Coppack, 1981).

A partir da execução do método de cálculo do amortecimento para os sinais amostrados temos o resultado representado na Figura 4.10, onde é possível observar a evolução da potência com o tempo de amostragem da principal ressonância encontrada em ambas as amostras. Nesta mesma figura é possível observar o valor da frequência encontrada assim como o valor do amortecimento calculado através do ajuste do modelo para cada uma das ressonâncias. 


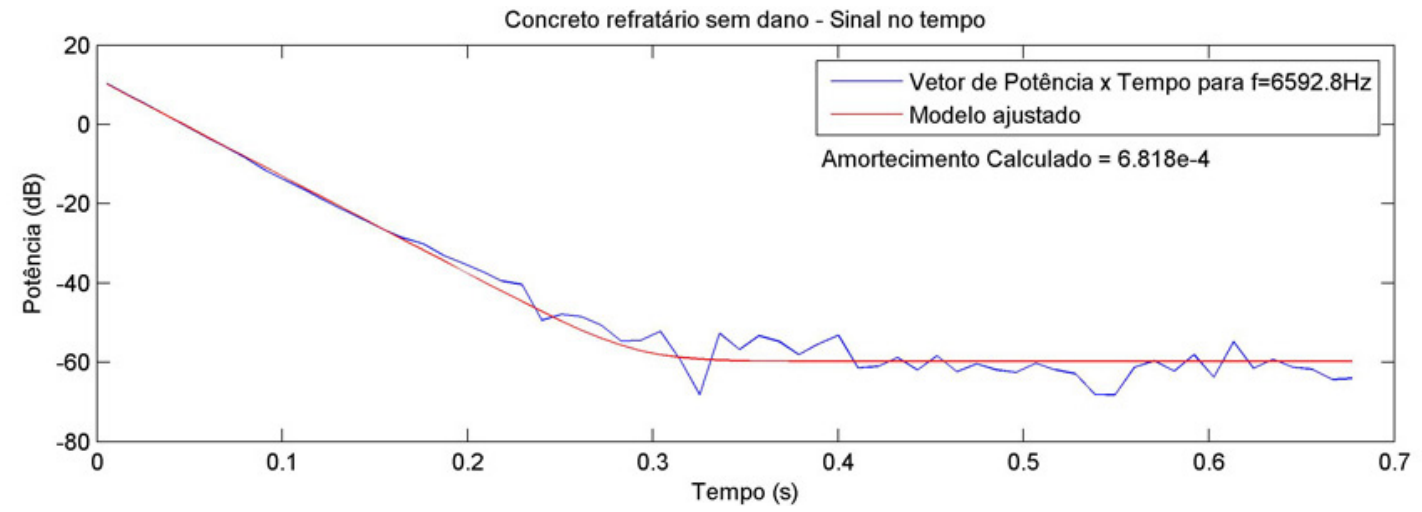

(a)

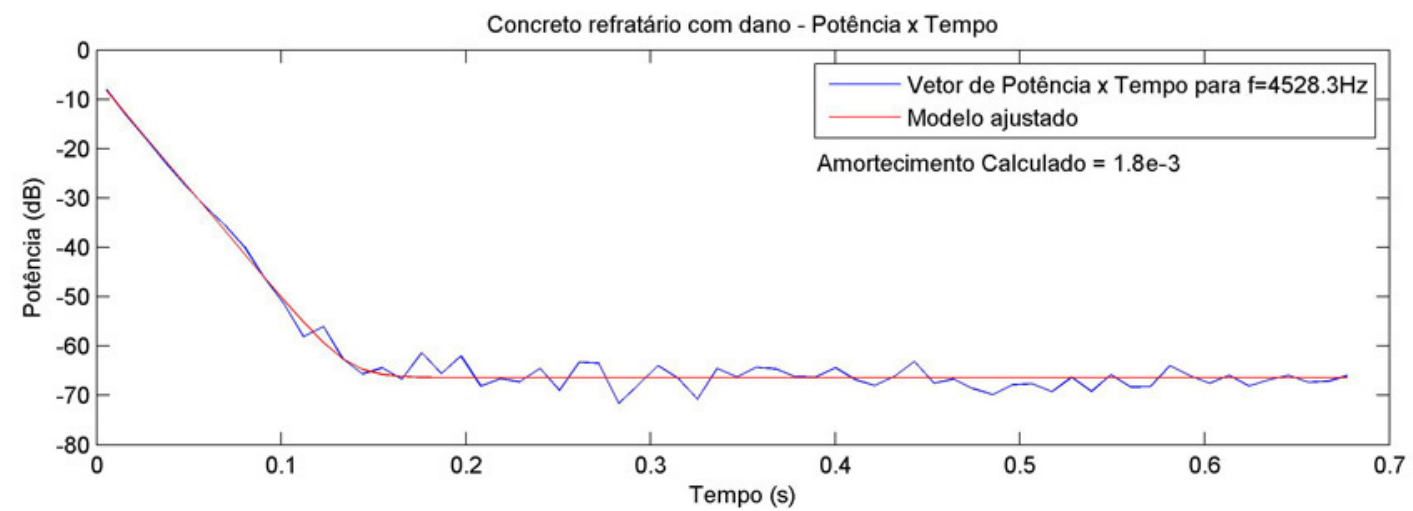

(b)

Figura 4.10: Variação da potência para a principal ressonância de cada amostra, modelos ajustados sobre a curva, valor das frequências de ressonância e valor do amortecimento calculado. (a) Concreto refratário com baixo teor de agregados (amostra 2) sem dano. (b) Concreto refratário com baixo teor de agregados (amostra 3) com dano por choque térmico.

Além do considerável desvio causado pelo dano na amostra que sofreu choque térmico, é possível observar uma grande diferença entre os amortecimentos calculados para as amostra com e sem dano. Esse aumento no amortecimento se deve principalmente ao aumento da dissipação da energia de vibração pelas trincas e micro-trincas geradas no choque-térmico (Dieterle e Bachmann, 1981).

A Tabela 4.2 sintetiza os resultados obtidos para ambas as amostras de concreto refratário com baixo teor de agregados. 
Tabela 4.2: Resumo dos resultados encontrados para as amostras de concreto refratário de alta alumina com baixo teor de agregados

\begin{tabular}{lcc}
\hline Amostra & $\begin{array}{c}\text { Frequência de } \\
\text { Ressonância }\end{array}$ & $\begin{array}{c}\text { Valor do } \\
\text { Amortecimento } \\
\text { Calculado }\end{array}$ \\
\hline Concreto refratário sem dano (amostra 2) & $6592.8 \mathrm{~Hz}$ & $6.818 \cdot 10^{-4}$ \\
\hline Concreto refratário com dano (amostra 3) & $4528.3 \mathrm{~Hz}$ & $1.8 \cdot 10^{-3}$ \\
\hline
\end{tabular}

\subsubsection{Refratário de Alta Alumina com Alto Teor de Agregados}

Concretos refratários comerciais apresentam diferentes composições de acordo com a aplicação do material assim como as propriedades desejadas para o mesmo. Os agregados, partículas sólidas de materiais refratários adicionados ao concreto que dará origem a peça monolítica de cerâmica refratária, tem como finalidade mais comum melhorar a capacidade do material de resistir às trincas que surgem do processo de choque térmico. Um dos mecanismos para essa melhora na resistência à fratura é o fato desses agregados servirem como barreiras mecânicas às trincas que surgem e tendem a se propagar pelo material (Cintra et al., 2010).

A Figura 4.11 mostra o sinal adquirido em função do tempo para a resposta de vibração de duas cerâmicas refratárias com alto teor de agregados. A Figura (a) representa o sinal da amostra sem danos por choque térmico e a Figura $4.11 \mathrm{~b}$ representa o sinal da amostra danificada por dois ciclos de choque térmico. 


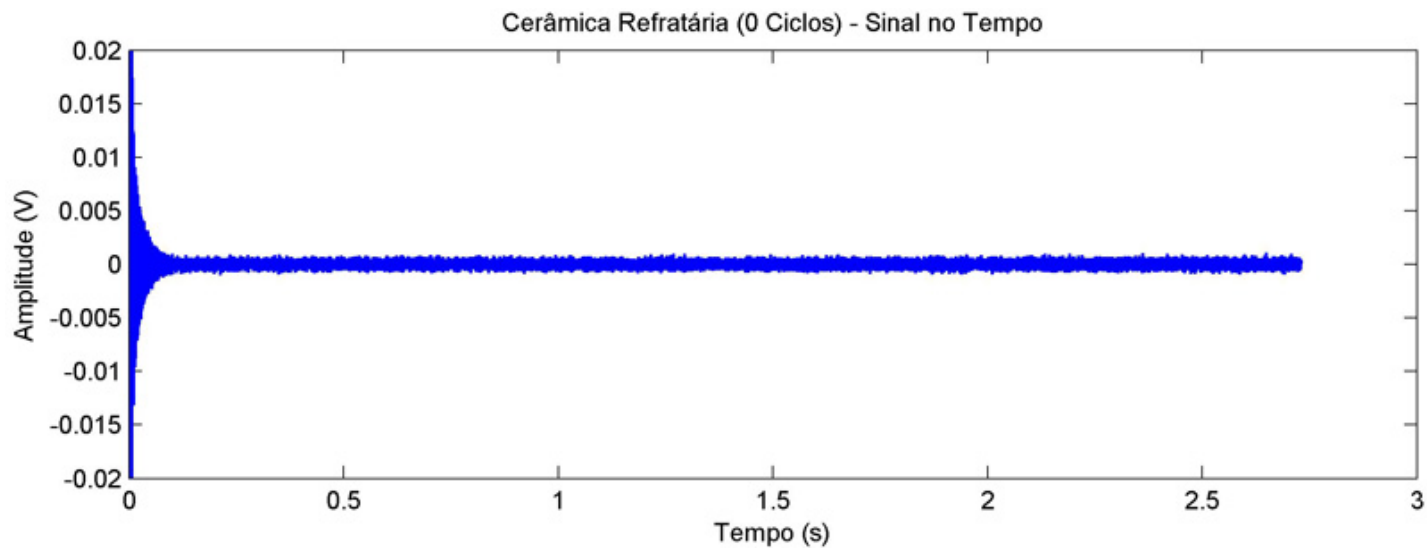

(a)

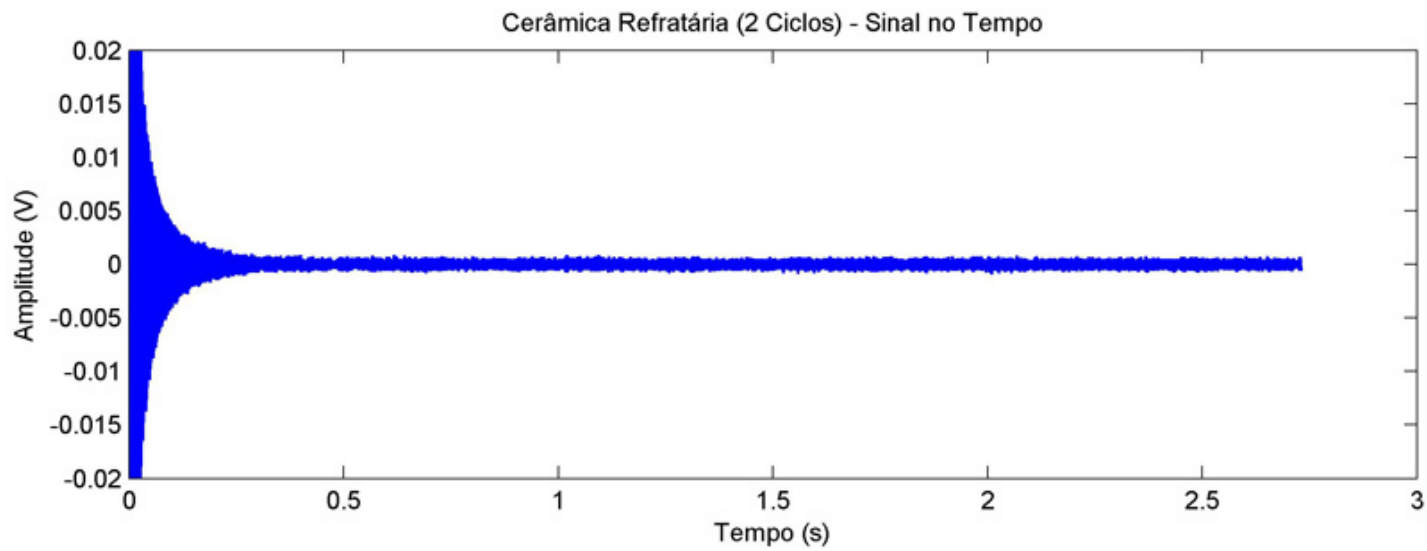

(b)

Figura 4.11: Sinais amostrados da amplitude de vibração pelo tempo de amostragem. (a) Sinal da amostra de concreto refratário com alto teor de agregados (amostra 4) sem dano. (b) Sinal da amostra de concreto refratário com alto teor de agregados (amostra 5) com dano por choque térmico.

Analogamente aos gráficos da Seção 4.3.1, as Figuras 4.12 e 4.13 se relacionam com a Figura 4.11 representando os espectros de magnitudes do sinal das amostras e também como a principal frequência de cada amostra varia sua potência em função do tempo. Nesta última é possível observar a variação da potência da frequência principal em função do tempo e também o modelo ajustado através do método de cálculo proposto, determinando assim o amortecimento desta frequência. 


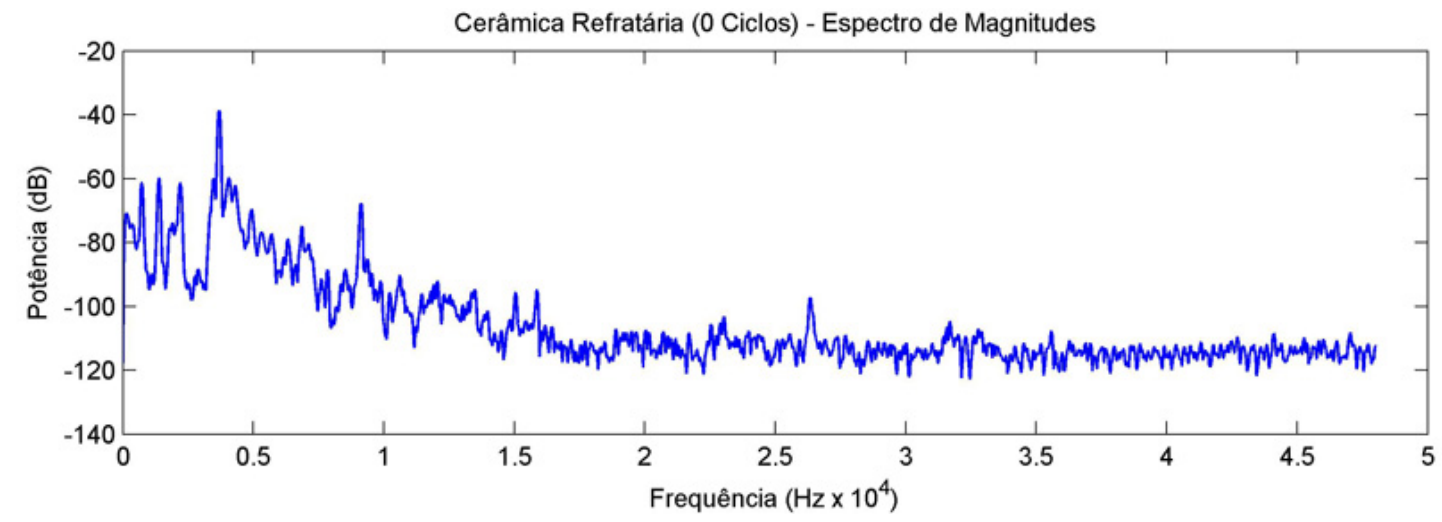

(a)

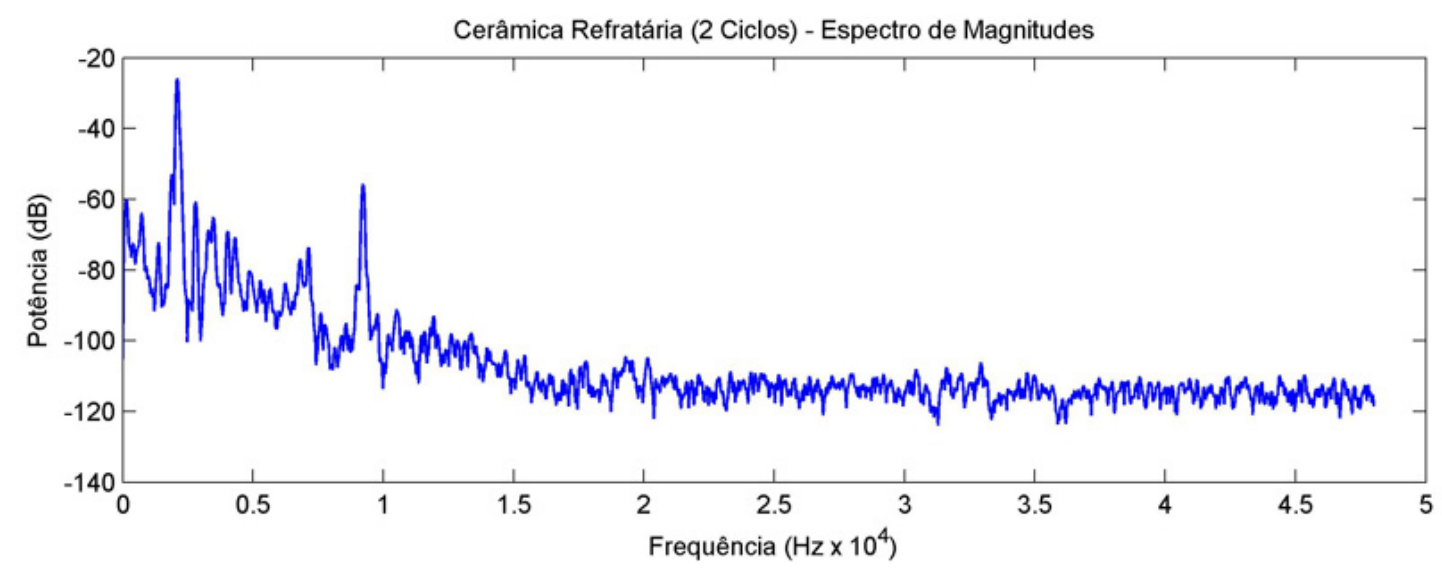

(b)

Figura 4.12: Espectros de magnitude dos primeiros 1024 pontos dos sinais representados na Figura 4.11. (a) Espectro de magnitude da amostra de concreto refratário com alto teor de agregados (amostra 4) sem dano. (b) Espectro de magnitude da amostra de concreto refratário com alto teor de agregados (amostra 5) com dano por choque térmico. 


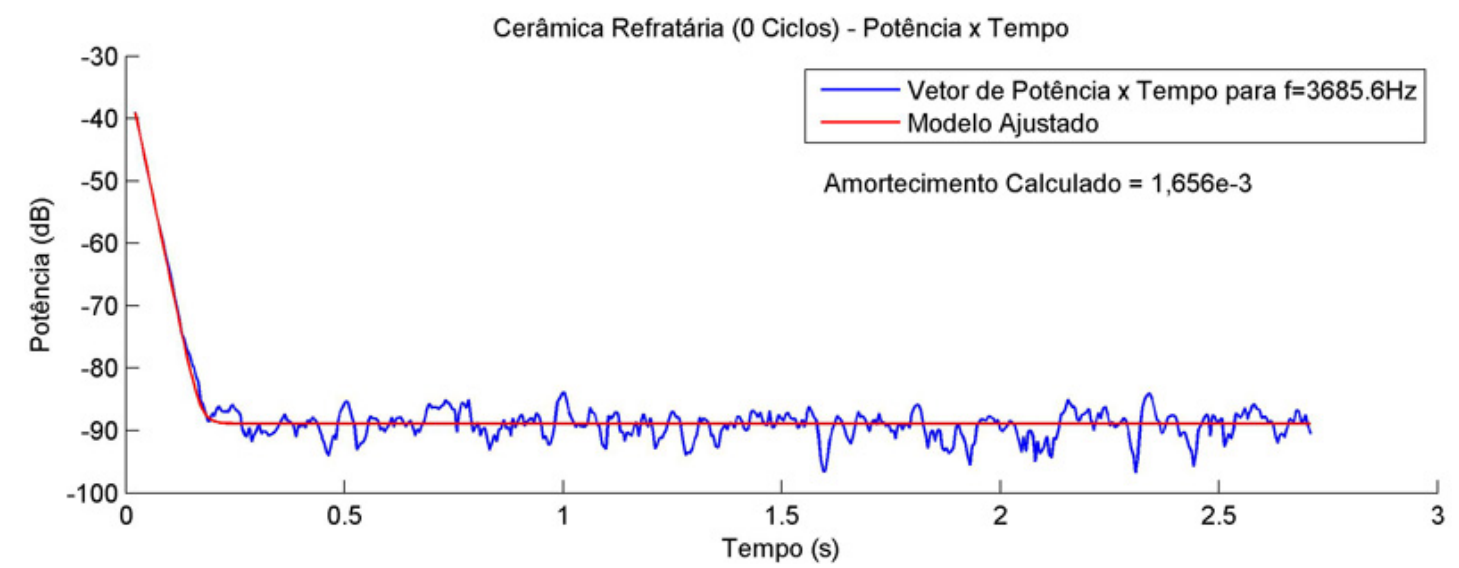

(a)

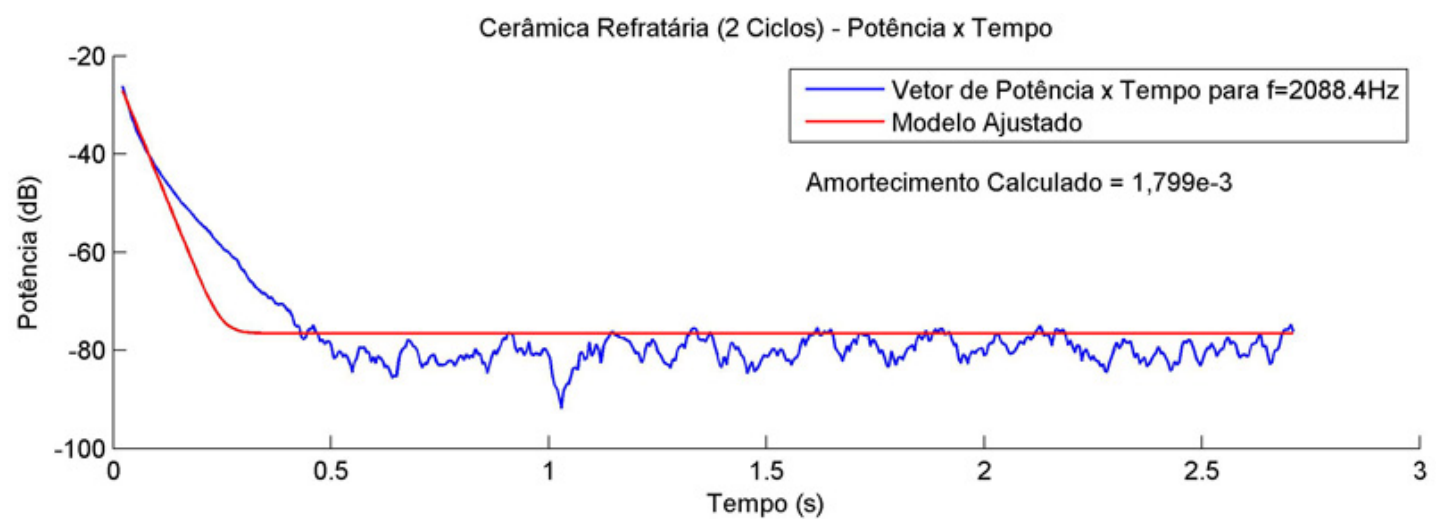

(b)

Figura 4.13: Variação da potência para a principal ressonância de cada amostra, modelos ajustados sobre a curva, valor das frequências de ressonância e valor do amortecimento calculado. (a) Concreto refratário com alto teor de agregados (amostra 4) sem dano. (b) Concreto refratário com alto teor de agregados (amostra 5) com dano por choque térmico.

A Tabela 4.3 sintetiza os resultados obtidos através do cálculo da frequência de ressonância e amortecimento para os sinais das Figuras 4.11.

É importante notar que, devido a maior complexidade dos materiais e do dano causado às suas estruturas, o sinal da variação da potência para as principais frequências de ressonância possuem alta influência de fenômenos não-lineares que distorcem esse sinal. Estes fenômenos fazem com o que o decaimento da energia da frequência de ressonância não siga necessariamente o modelo proposto.

Esse resultado acarreta em uma maior imprecisão e erro no cálculo. Ainda assim é possível 
observar que ao menos num pequeno trecho deste decaimento o modelo parece se ajustar ao sinal de forma coerente fazendo valer o resultado, senão como valor do amortecimento, como referência para comparação de resultados posteriores da mesma amostra após novos ciclos de choque térmico.

Tabela 4.3: Resumo dos resultados encontrados para as amostras de concreto refratário com alto teor de agregados

\begin{tabular}{lcc}
\hline Amostra & $\begin{array}{c}\text { Frequência de } \\
\text { Ressonância }\end{array}$ & $\begin{array}{c}\text { Valor do } \\
\text { Amortecimento } \\
\text { Calculado }\end{array}$ \\
\hline Concreto refratário sem dano (amostra 4) & $3685.6 \mathrm{~Hz}$ & $1.656 \cdot 10^{-3}$ \\
\hline Concreto refratário com dano (amostra 5) & $2088.4 \mathrm{~Hz}$ & $1.799 \cdot 10^{-3}$ \\
\hline
\end{tabular}

\subsubsection{Refratário de Silico-Aluminoso Impregnado com Coque}

As amostras de concreto refratário silico-aluminoso impregnado coque são oriundas do processo de craqueamento catalíco de petróleo para separação de seus produtos. O objetivo desta seção é exemplificar outra dentre as diversas áreas passíveis de aplicação do método de cálculo de amortecimento para caracterização e estudo de amostras de concreto refratário.

A Figura 4.14 mostra o sinal como foi amostrado em função do tempo para as duas amostras, com e sem dano por choque-térmico. Associada aos sinais da Figura 4.14, a Figura 4.15 mostra os espectros de magnitude das amostras. 


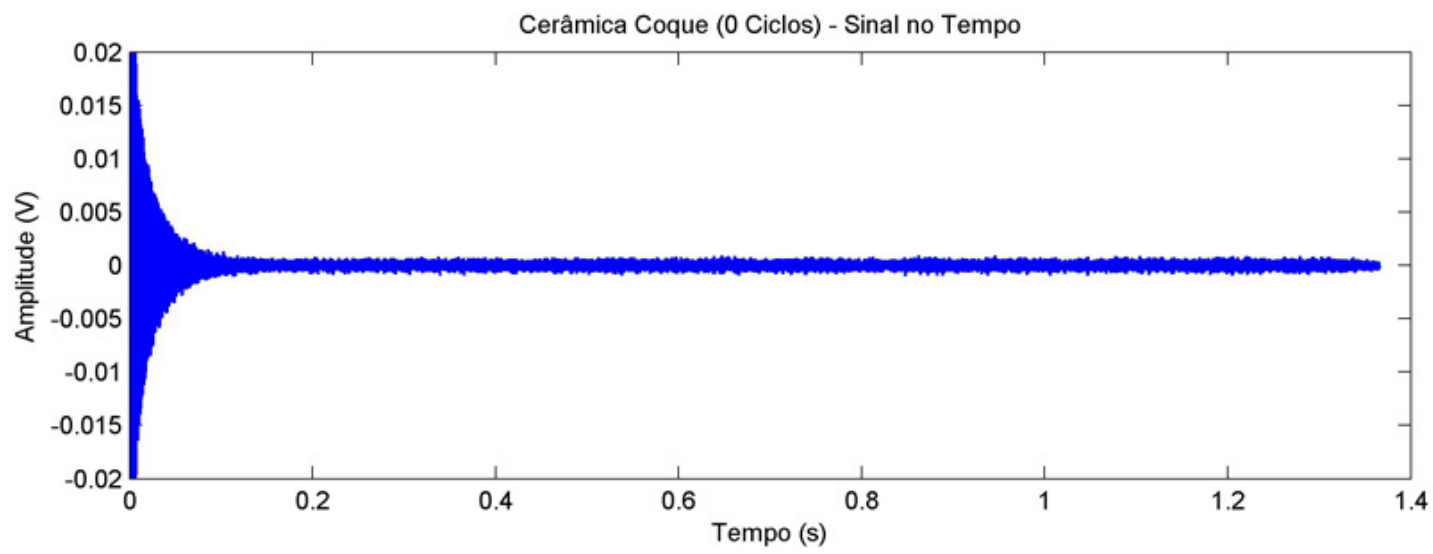

(a)

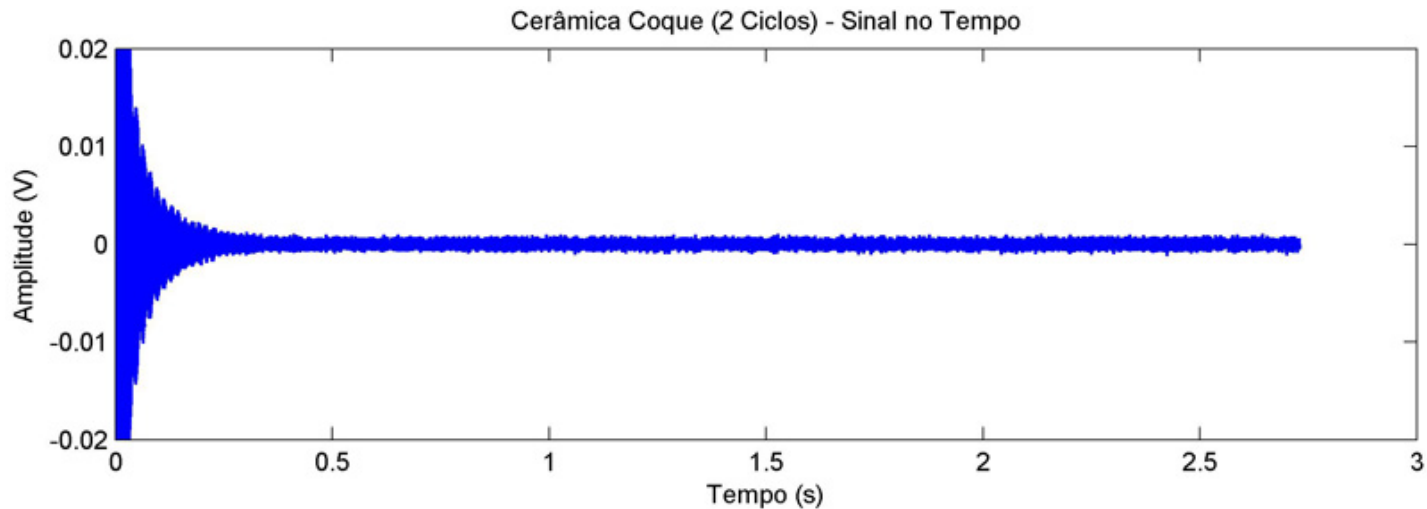

(b)

Figura 4.14: Sinais amostrados da amplitude de vibração pelo tempo de amostragem. (a) Sinal da amostra de concreto refratário impregnado com coque (amostra 6) sem dano. (b) Sinal da amostra de concreto refratário impregnado com coque (amostra 7) com dano por choque térmico. 


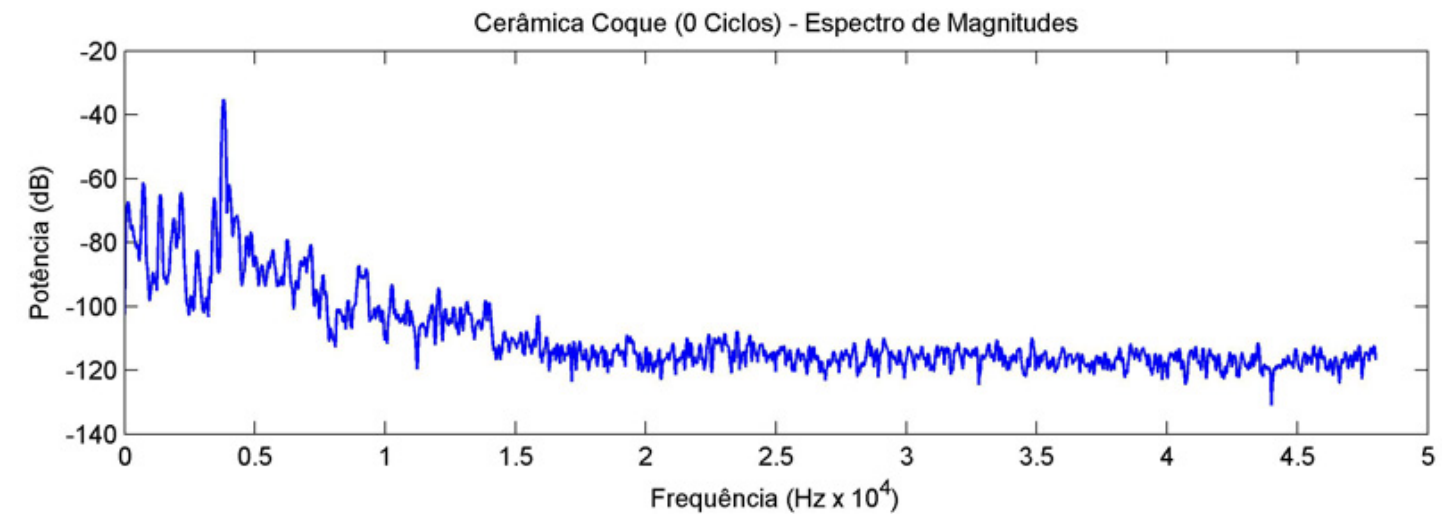

(a)

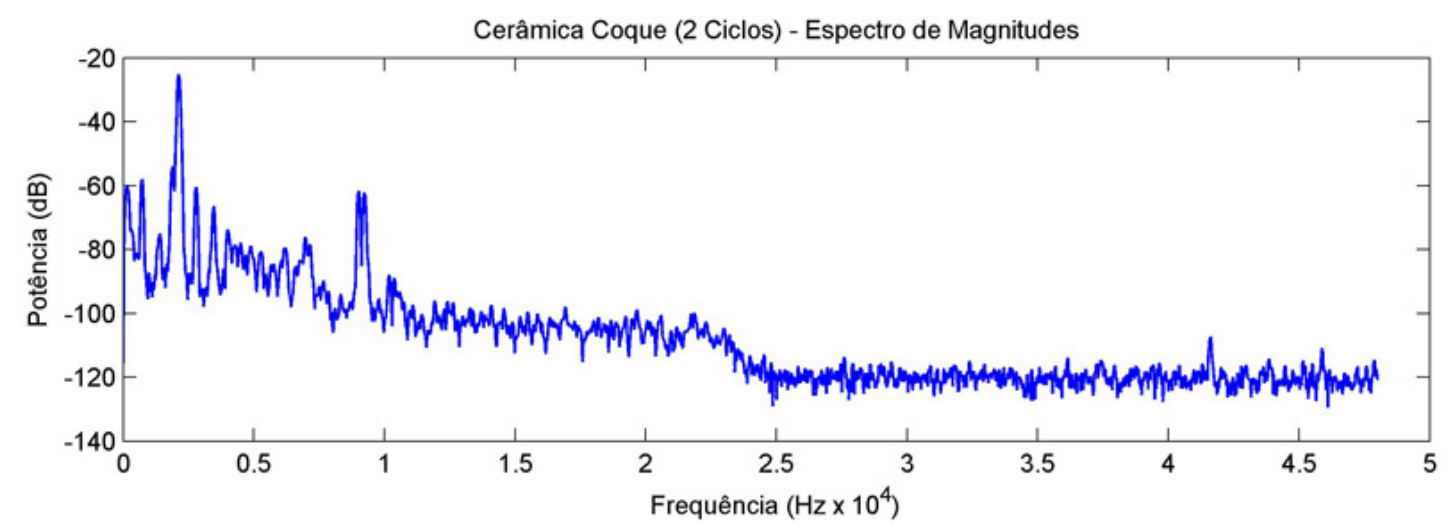

(b)

Figura 4.15: Espectros de magnitude dos primeiros 1024 pontos dos sinais representados na Figura 4.14. (a) Espectro de magnitude da amostra de concreto refratário impregnado com coque (amostra 6) sem dano. (b) Espectro de magnitude da amostra de concreto refratário impregnado com coque (amostra 7) com dano por choque térmico.

Para o principal pico de ressonância encontrado na Figura 4.15a (amostra sem dano) e na Figura 4.15b (amostra com dano) são apresentados os vetores de decaimento de potência e o modelo ajustado sobre estes através do método de cálculo. O resultado pode ser observado na Figura 4.16. 


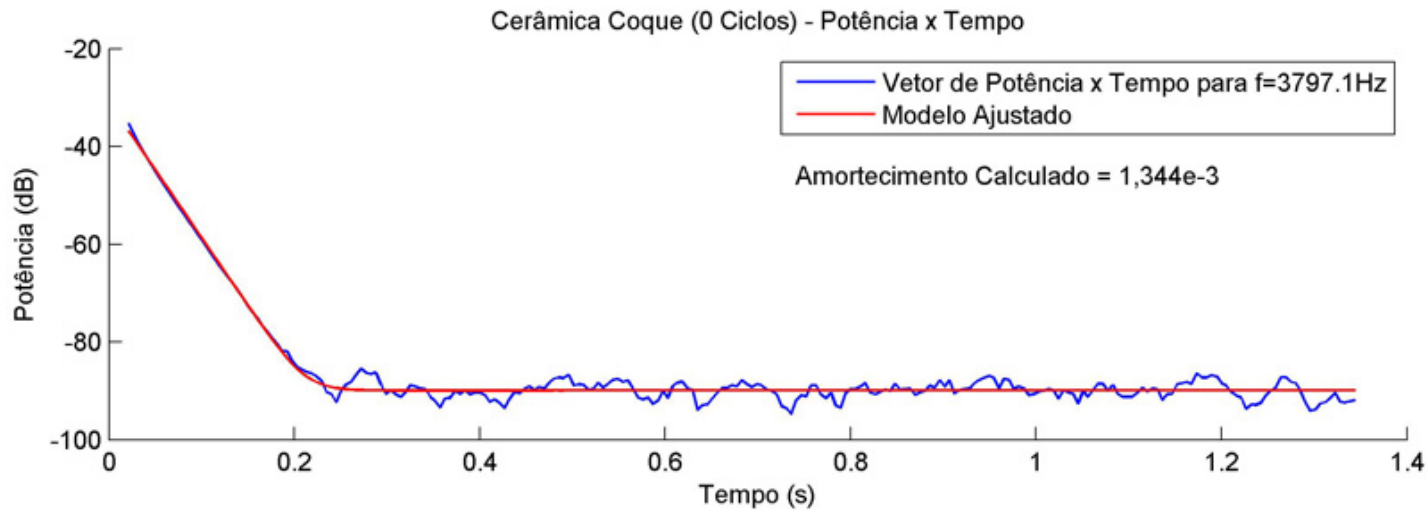

(a)

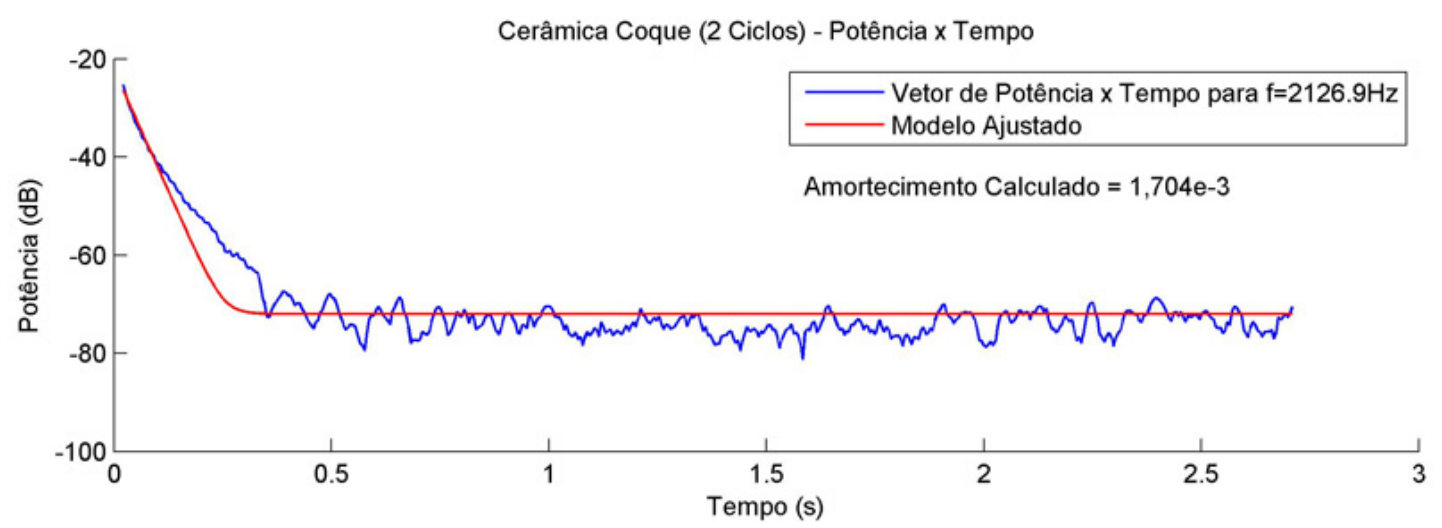

(b)

Figura 4.16: Variação da potência para a principal ressonância de cada amostra, modelos ajustados sobre a curva, valor das frequências de ressonância e valor do amortecimento calculado. (a) Concreto refratário impregnado com coque (amostra 6) sem dano. (b) Concreto refratário impregnado com coque (amostra 7) com dano por choque térmico.

Assim como foi observado nos resultados da Seção 4.3.2, essas amostras após os choques térmicos sofridos também apresentam fenômenos não-lineares no decaimento da energia da principal frequência de ressonância. O resultado disso é uma pior adequação do modelo proposto aos dados.

O resumo dos resultados dessas amostras pode ser observado na Tabela 4.4. 
Tabela 4.4: Resumo dos resultados encontrados para as amostras de concreto refratário impregnado com coque

\begin{tabular}{lcc}
\hline Amostra & $\begin{array}{c}\text { Frequência de } \\
\text { Ressonância }\end{array}$ & $\begin{array}{c}\text { Valor do } \\
\text { Amortecimento } \\
\text { Calculado }\end{array}$ \\
\hline Concreto refratário sem dano (amostra 6) & $3797.1 \mathrm{~Hz}$ & $1.344 \cdot 10^{-3}$ \\
\hline Concreto refratário com dano (amostra 7) & $2126.9 \mathrm{~Hz}$ & $1.704 \cdot 10^{-3}$ \\
\hline
\end{tabular}




\section{Capítulo 5}

\section{Discussão e Conclusão}

No decorrer deste trabalho foi apresentada uma metodologia associada a um algoritmo para a determinação do amortecimento em materiais através da técnica de excitação por impulso e observação da ressonância livre.

Os resultados obtidos correspondem a uma estimativa do amortecimento interno dos materiais sob a restrição da perda de energia da ressonância ser descrita por um modelo de amortecimento viscoelástico. Quando aplicado a um sinal simulado que descreve uma ressonância que atende ao amortecimento viscoelástico, o algoritmo de cálculo demonstrou sua eficácia tendo sido possível recuperar o valor do amortecimento e da frequência de ressonância usados na geração do sinal com um erro muito baixo em ambos os valores.

O resultado obtido pelo algoritmo quando aplicado a ressonância de uma barra de alumina densa corresponde à valores descritos em literatura. A alumina, devido a sua baixa anisotropia, apresenta uma ressonância que se compatibiliza muito bem ao modelo viscoelástico, fica isso bem representado pelo ajuste do modelo aos dados da ressonância.

O valores encontrados como resultados para os concretos refratários comerciais de alta alumina não puderam ser comparados à valores de literatura por que há grandes diferenças entre concretos refratários, composições muito variadas, que afetam diretamente seu amortecimento. Além disso, é conhecida uma grande dependência entre o amortecimento e a umidade em materiais porosos.

Apesar desses fatores, é clara a degradação do sinal de ressonância no material que sofreu dano por choque-térmico e o amortecimento calculado foi capaz de apresentar essa diferença identificando uma maior dissipação de energia neste material. 
A avaliação do amortecimento para materiais deve ser feita de maneira cuidadosa e levando em consideração fatores que influenciam diretamente a dissipação de energia da ressonância, como por exemplo a umidade.

Além disso, foram observados fenômenos não-lineares na ressonância de materiais muito danificados ou muito heterogêneos (cerâmicas com alto teor de agregados e compósitos). Esses fatores podem levar a erros de cálculo, porém geralmente são de fácil percepção ao observar o ajuste do modelo aos dados.

Pela maneira como foi implementado o modelo de ajuste não-linear, o algoritmo enfatiza a redução de erro no ajuste em valores de amplitude grandes, fazendo com que na maioria dos casos o ajuste seja enfatizado para a porção inicial do sinal (maior amplitude). Esse fenômeno pode ser facilmente observado em casos em que o decaimento ocorre de maneira não-linear.

Uma possível solução para esse problema é criar um mecanismo de ponderação do sinal e do modelo para diminuir a diferença absoluta de valores entre as amplitudes mais altas no início do sinal e do nível de ruído observado na porção final do sinal. Um exemplo de sistema de ponderação plausível seria aplicar um expoente entre 0 e 1 ao sinal e ao modelo calculado no ajuste.

Este algoritmo foi também implementado de forma embarcada em DSP (Analog Devices SHARC ADSP-21262) em uma plataforma de processamento de sinais com sistema de aquisição similar ao utilizado pelo MATLAB. O resultado obtido nessa plataforma foi equivalente ao obtido com o uso do MATLAB porém em tempo real (dados não apresentados).

\subsection{Próximos Passos}

Como proposta de estudos futuros, o estudo da não-linearidade observada nos materiais com alta severidade de dano poderia fornecer informações mais qualitativas com relação a estrutura interna do material e sua composição.

Existem modelos de não-linearidade já conhecidos como o modelo de amortecimento histerético, em que o amortecimento depende da frequência, e outros onde há uma alta dependência do amortecimento e da frequência de oscilação com a amplitude de vibração. A aplicação desses modelos aos sinais adquiridos poderia melhorar significativamente os resultados nesses casos atípicos. 
Este estudo deveria incluir também a melhoria do ajuste não-linear para que o algoritmo não fosse influenciado de maneira tão significativa pelas grandes amplitudes do sinal.

Por fim, seria ainda interessante comparar estes resultados com outros métodos de cálculo de amortecimento, como o método da largura de banda de meia potência e outros que utilizam transformadas wavelet para observação do domínio de tempo-frequência. 


\section{Referências Bibliográficas}

ASTM, C. (1995). 1259-94, standard test method for dynamic youngs modulus, shear modulus, and poissons ratio for advanced ceramics by impulse excitation of vibration. American Society for Testing and Materials Annual Book of Standards, 15:336-384.

Chowdhury, S. (1999). Damping characteristics of reinforced and partially prestressed concrete beams. Tese de Doutorado, Griffith University.

Cintra, G., Braulio, M., Bittencourt, L., e Pandolfelli, V. (2010). Tamanho de grão do mgo e seus efeitos na resistência ao choque térmico de concretos refratários espinelizados in-situ. Cerâmica, 56(337):15-22.

Cooley, J. e Tukey, J. (1965). An algorithm for the machine calculation of complex fourier series. Mathematics of computation, 19(90):297-301.

Coppack, T. (1981). A method for thermal cycling refractories and an appraisal of its effect by a non-destructive technique. Trans. J. Br. Ceram. Soc., 80(2):43.

Coppola, J. e Bradt, R. (1973). Thermal-shock damage in sic. J. Am. Ceram. Soc, 56(4):215-8.

De Silva, C. (2007). Vibration damping, control, and design. CRC Press.

Dieterle, R. e Bachmann, H. (1981). Experiments and models for the damping behaviour of vibrating reinforced concrete beams in the uncracked and cracked conditions. Bericht $\mathrm{Nr}$, 119.

Hasselman, D. (1969). Unified theory of thermal shock fracture initiation and crack propagation in brittle ceramics. J. Am. Ceram. Soc, 52(11):600-604.

Kaiser, J. e Schafer, R. (1980). On the use of the i 0-sinh window for spectrum analysis. IEEE Transactions on Acoustics, Speech and Signal Processing, 28(1):105-107. 
Kingery, W. (1955). Factors affecting thermal stress resistance of ceramic materials. J. Am. Ceram. Soc, 38(1):3-15.

Lazan, B. (1968). Damping of materials and members in structural mechanics. Pergamon press Oxford.

Lemmens, J. (1990). Impulse excitation: A technique for dynamic modulus measurement. Dynamic elastic modulus measurements in materials, pp. 90-99.

Levenberg, K. (1944). A method for the solution of certain nonlinear problems in least squares. Quart. Appl. Math, 2(2):164-168.

Lord, J. D. e Morrell, R. (2006). A national measurement good practice guide - elastic modulus measurement.

Madsen, K., Nielsen, H., e Tingleff, O. (2004). Methods for non-linear least squares problems. April.

Marquardt, D. (1963). An algorithm for least-squares estimation of nonlinear parameters. Journal of the Society for Industrial and Applied Mathematics, 11(2):431-441.

Mathworks (15/07/2010). Matlab documentation. http://www.mathworks.com.

Oppenheim, A., Schafer, R., e Buck, J. (1989). Discrete-time signal processing. Prentice hall Englewood Cliffs, NJ, 2nd ed.

Papoulis, A. (1984). Probability, Random Variables, and Stochastic Processes. McGraw-Hill.

Pickett, G. (1945). Equations for computing elastic constants from flexural and torsional resonant frequencies of vibration of prisms and cylinders. In Proceedings, pp. 846-865.

Proakis, J. e Manolakis, D. (1996). Digital signal processing: principles, algorithms, and applications. Prentice Hall New Jersey.

Slepian, D. e Pollack, H. (1961). Prolate spheroidal wave functions fourier analysis and uncertainty (1). Bell System Tech. J, 40:43-64.

Sun, W. e Yuan, Y. (2006). Optimization theory and methods: nonlinear programming. Springer Verlag.

Thorby, D. (2008). Structural dynamics and vibration in practice: an engineering handbook. Elsevier/Butterworth-Heinemann. 
Tonnesen, T. e Telle, R. (2007). Thermal shock damage in castables: Microstructural changes and evaluation by a damping method. In Ceramic Forum International, vol. 84.

Truesdell, C. (1960). The rational mechanics of flexible or elastic bodies. Introduction to Leonhardi Euleri Opera Omnia, Ser. secunda XI, Fussli, Zurich, pp. 1638-1788.

Welch, P. (1967). The use of fast fourier transform for the estimation of power spectra: a method based on time averaging over short, modified periodograms. IEEE Transactions on Audio and Electroacoustics, 15(2):70-73. 